Estudios Geográficos, LXIX, 265, pp. 453-493, julio-diciembre 2008

ISSN: 0014-1496

elSSN: $1988-8546$

doi: 10.3989/estgeogr.0436

\title{
El agua como recurso escaso y sus problemas en la España actual
}

\section{Water, a scarce resource and its currents problems in Spain}

Joaquín Bosque Maurel

El agua resulta ser la riqueza económica por excelencia; para los hombres es más riqueza que la hulla y el oro. El agua es para un Estado y para un Pueblo, la soberana riqueza. Es alimento. Es fuerza. Es camino.

Jean Brunhes

Géographie humaine de la France, 1920

El uso del agua siempre ha sido un problema en España. A menudo se ha hablado, y no sólo en la actualidad, de una "guerra del agua" o "por el agua", al menos en determinadas regiones o comarcas españolas (J. Brunhes, 1904; A. López Gómez, 1951). El positivo desarrollo económico español de los últimos decenios del siglo XX y los primeros años del XXI, incrementó el consumo de agua tanto en la agricultura, su principal uso todavía, como en la industria. $Y$, no menos, en el consumo público y privado, sobre todo urbano, exacerbado por las exigencias, a veces desmesuradas, del creciente turismo de calidad. En paralelo, se tropezaba con las ya escasas posibilidades de creación de nuevos aprovechamientos hidráulicos — presas y embalses - a nivel regional y nacional y con el desarrollo de una conciencia ecologista contraria al "gigantismo" de las últimas obras públicas y a sus

* Universidad Complutense de Madrid y Real Sociedad Geográfica. 
peligrosas, a veces, servidumbres y perjuicios medioambientales $y$, no menos, del hábitat rural tradicional.

Un ecologismo que, además, analizaba, quizá con excesiva dureza, a lo que aparecía casi como única solución, el modelo de "presa y trasvase" iniciado a comienzos del Novecientos con los escritos de Joaquín Costa y algunos otros Regeneracionistas y culminado durante los cuarenta años del Franquismo. Se discutía, así, el mantenimiento de planteamientos nacidos tímidamente con el Plan Gasset de 1904 y, ampliados y sostenidos con nuevas ideas en los años treinta por Manuel Lorenzo Pardo, y llevados a la práctica en los años setenta del mismo siglo XX con el calificado de "faraónico" trasvase Tajo-Segura (A. López Bermúdez, 1969), y el anteproyecto de 1974, pronto olvidado, tras un acalorado debate entre las instituciones y las opiniones públicas aragonesas y catalanas, de otro trasvase que desde el Bajo Ebro aliviaría la escasez hidráulica de Cataluña (E. Barrenechea, 1974).

Tensiones y debates que, desde entonces, han avivado la polémica y acalorado las relaciones entre las regiones cedentes y las receptoras, de los discutidos y politizados Planes Hidrológicos de 1993, 2000 y 2004. Ha nacido así la búsqueda de una "nueva cultura del agua" que pueda enfrentase con la exigencia de una imprescindible reforma de las consecuencias no siempre positivas del desarrollo de la irrigación y, quizá más, de los modos de usos urbanos y turísticos del agua. Con una finalidad última, la búsqueda de una gestión de las reservas hidráulicas consecuente con el principio, ya participado y difundido por las Naciones Unidas, del "agua, recurso escaso y finito" (ONU, 1977).

\section{AlgunOs ANTECEDENTES HISTÓRICOS}

Los cambios producidos en la estructura de la agricultura tradicional española, siempre muy ligada al medio físico peninsular, han significado una transformación de esas condiciones naturales $\mathrm{y}$, en cierto sentido, una auténtica "intervención sobre el clima" (A. Cabo Alonso, 1988). Unos cambios que siendo muy antiguos han alcanzado su mayor desarrollo a lo largo del último siglo. Una intervención que era imprescindible y obligada en la Iberia seca de Jean Brunhes (1904), la mayor parte de la Península Ibérica.

El regadío, que es el punto de partida del cambio y su consecuencia inmediata, tiene orígenes muy remotos, neolíticos, como se han hecho patentes en diversas excavaciones llevadas a cabo en el alto Guadiana Menor (Orce), en el valle del Genil y a lo largo del curso del Ebro. Más 
tarde, fueron objeto de una considerable ampliación e importantes mejoras durante la etapa romana. Existen referencias varias en autores como Plinio el Viejo y San Isidoro de Sevilla y en la Ilamada Ley de Osuna, aparte de numerosos recuerdos arqueológicos como los pequeños embalses que abastecían a Emérita Augusta (Mérida), entre otras obras hidráulicas —canales y acueductos- dispersas por todo el país, por ejemplo, la Huerta de Valencia y la Vega de Granada (A. López Gómez, 1974; AlMudayna, 1991).

Los musulmanes ampliaron y mejoraron el área regada, introduciendo sobre todo nuevas formas de uso y una nueva relación entre la propiedad del suelo y el agua para riego. Abderramán III ordenó la construcción de una acequia en Écija y Alhaquen II favoreció obras similares en las Huertas levantinas y en la Vega de Granada, que, nacidas con Roma, fueron ampliadas y reguladas en el siglo XIII. Además de introducir nuevos sistemas de elevación y uso del agua de origen oriental, como norias y ruedas y minas de agua (J. Caro Baroja, 1988), desarrollaron toda una legislación no escrita que parece haberse perpetuado tras la Reconquista y mantenido vigente - Tribunal de las Aguas valenciano- hasta el momento actual, a pesar de la promulgación de la primeras Leyes del Agua de 1866 y 1879. Y que parte del principio básico de que la propiedad de la tierra lleva inherente el derecho al uso del agua. Una fórmula no siempre aceptada.

Obras y preocupaciones similares existieron en los reinos cristianos, especialmente en la Corona de Aragón y en los regadíos del Ebro y sus afluentes. En el siglo XVI, durante el reinado de Carlos I, se plantearon las primeras grandes obras hidráulicas modernas, iniciándose los canales Imperial de Aragón y de Tauste en el Ebro, y se proyectaron diversos planes sin efecto inmediato en el Duero y el Tajo. El siglo XVIII fue un momento de extraordinaria preocupación por la mejora y racionalización del campo español. Aparte de una reflexión generalizada sobre lo que Jovellanos denominó "la remoción de los estorbos que se oponen al... estado progresivo de la agricultura" (1994, pág. 12), se llevó a cabo una importante política hidráulica.

Entre otras muchas obras de interés público, se construyeron la Acequia Real en el Júcar, el Canal de la Infanta Carlota en el Llobregat y el de Huéscar en el Guardal, un afluente del Guadiana Menor y el Guadalquivir, el frustrado Canal del Guadarrama, se reanudaron y finalizaron los Canales Imperial de Aragón y de Tauste (1790) en el Ebro y se llevó a cabo el de la Tierra de Campos en el Duero (1804), en los que al interés del regadío se unió el transporte de mercancías. Finalmente, se construyeron los dos primeros embalses modernos de Puentes y Valdeinfierno (1788) en el Guadalentín, y se 
comenzaron los riegos de Urgel, terminados y puestos en marcha en la siguiente centuria (J. I. Fernández Marco, 1961; A. López Gómez, 1971; J. Ma Sanz García, 1988; Al-Mudayna, 1991).

Todo un proceso teórico y práctico que fue la base del gran avance del regadío durante el siglo XX. Regeneracionistas como Joaquín Costa (1880 y 1892) y Ricardo Macías Picavea (1899), buenos conocedores de las propuestas "ilustradas", hicieron de la política hidráulica uno de sus máximos objetivos convirtiéndola en "el soporte ideológico del regadío en España hasta el año 1959" (E. Nadal, 1981, pág. 136). En 1902, se aprobó el primer Plan Nacional de Obras Hidráulicas del Ministro de Fomento Rafael Gasset, anticipo de las propuestas posteriores. Durante la Dictadura del general Primo de Rivera, el ministro conde de Guadalhorce estableció las bases imprescindibles para el desarrollo del regadío futuro con la creación de las Confederaciones Hidrográficas (1926) (J. Velarde Fuertes, 1968).

Finalmente, en el transcurso de la II República, Manuel Lorenzo Pardo (1931 y 1933), con su Plan de 1933, sentaría el punto de partida del más serio y concienzudo anteproyecto de obras hidráulicas de la historia española, Ilevado a la práctica en parte entre 1940 y 1975, como base de "una política de riegos y bosques" junto con otras Leyes y Proyectos que lo continuaron en lo fundamental — La Ley De Bases para la Colonización de Grandes Zonas (1939), la creación del Instituto Nacional de Colonización (1940) y el Plan Nacional de Obras Hidráulicas de 1943 programado por el ministro Alfonso Peña Boeuf-y mantenidas después de 1975, con un ritmo muy inferior, hasta el momento actual (N. Ortega Cantero, 1979; AA. VV., 1989).

TABla 1. Evolución DE LA SUPERfiCIE REGADA (1900-2005)

\begin{tabular}{cccr} 
Año & Cultivos herbáceos & Cultivos leñosos & Total \\
\hline 1900 & - & - & 900.000 \\
1918 & - & - & 1.200 .000 \\
1930 & - & - & 1.350 .000 \\
1950 & 1.150 .000 & 309.000 & 1.450 .000 \\
1960 & 1.468 .000 & 342.000 & 1.828 .000 \\
1970 & 1.710 .000 & 488.000 & 2.198 .000 \\
1975 & 2.049 .000 & 568.000 & 2.617 .000 \\
1980 & 2.214 .000 & 608.000 & 2.822 .000 \\
1985 & 2.345 .000 & 662.000 & 3.213 .000 \\
1990 & - & - & 3.300 .700 \\
1995 & - & - & 3.500 .000 \\
2000 & - & - & 3.874 .000 \\
2005 & - & & \\
& & &
\end{tabular}

Fuente: Ministerio de Fomento. 
A finales del siglo XIX se estimaba que el regadío alcanzaba una superficie de 900.000 ha, y, poco después, en 1918, la superficie regada se calculaba en 1.200.000 ha. Desde entonces el avance de la irrigación fue continuo: 1.450 .000 en $1950,2.617 .000$ en $1975,3.213 .000$ en 1985 y casi 3.900 .000 en 2000 y más de 4.200 .000 en 2005. Si en 1900 el regadío significaba apenas el $5 \%$ de las tierras cultivadas, a comienzos del siglo XXI comprende en torno al $15 \%$ (tabla 1).

Cifras oficiales del Ministerio de Agricultura, pero a las que cabe añadir un $20 \%$ más, "ya que no todas las pequeñas derivaciones se declaran, ni se declara tampoco toda la tierra que se alcanza a regar con cada perforación particular" (A. Cabo Alonso, 1988: 26). En este incremento más o menos oficial podrían encontrarse una parte de las 350.000 nuevas hectáreas de regadío aparecidas en un estudio con satélite sobre el cambio del suelo entre 1990 y 2000 realizado por el Instituto Geográfico Nacional y dado a conocer el año 2005. En esa cifra entran cultivos regados todo el año —arrozales, frutales, hortalizas, viñedos y olivares- y que, centrados especialmente a todo lo largo del litoral mediterráneo, forman parte de zonas con un claro déficit de agua y que, por ello, dificultan la gestión del agua al menos en épocas de sequía según la Secretaría para la Biodiversidad y Ordenación del Territorio del Ministerio de Medio Ambiente (R. Méndez, 2005).

En el desarrollo último del regadío, desde los años treinta del siglo $\mathrm{XX}$, hay que distinguir un periodo de iniciativa pública dominante, que desde 1940 y hasta 1975 correspondió al Instituto Nacional de Colonización (INC) y, más tarde, al Instituto de la Reforma Agraria (IRYDA) realizadores del $61,8 \%$ de todas las tierras ganadas por el riego hasta la fecha. Así, el Estado ha sido el responsable de la mayor parte de las obras más espectaculares e importantes realizadas desde 1900.

Entre ellas cabe distinguir el Plan Badajoz que, junto con los riegos cacereños del Tajo, ha aportado a Extremadura 115.100 nuevas hectáreas, un $108 \%$ de aumento. También, los regadíos de La Mancha, 171.700 ha (124\%), de los cuales una suma importante es de origen subterráneo, aparte su relación con el trasvase Tajo-Segura. Los del Duero suman 186.800 (84\%), muy ligados a la producción hidroeléctrica procedente de las obras implantadas en los Arribes en íntima colaboración con Portugal. Los Riegos del Alto Aragón, una de las aspiraciones de Joaquín Costa, aún no finalizados, que han incrementado en 89.000 ha, sólo un 30\%, el regadío aragonés. Finalmente, los planes de irrigación del Guadalquivir han aportado 262.800 nuevas ha, lo que supone un incremento del $68 \%$ y han convertido al antiguo Al-Andalus en la región con más tierras irrigadas de la Península. Asimismo, Andalucía, con algunos de los 
más antiguos regadíos hispanos, como las Vegas de Granada, Sevilla y Málaga, se ha reconvertido en la primera región agraria de España - ya lo fue durante la Hispania romana-y en una de las pioneras, en muchos sentidos, de la agricultura de la Unión Europea (J. Bosque Maurel, 2007).

\section{SitUACIÓN ACTUAL}

Un regadío de viejo origen, romano y musulmán, en fin, que incrementado modernamente con los creados y recreados en los tres siglos últimos, especialmente en la segunda mitad del Novecientos, ha llegado a ser la base de la "nueva" agricultura española, gracias sobre todo a su capacidad de innovación tecnológica que estando presente en todos los regadíos no lo está por igual en todos los casos.

La aparición de estos "nuevos paisajes" agrícolas se ha visto acompañada - y provocada - por novedosas técnicas de riego, de cambios en las formas y usos de los cultivos — por ejemplo, la expansión de la agricultura ecológica o de la generalización y mejora de los cultivos tempranos- y de la introducción de unos principios empresariales tanto en la racionalización de la producción como, más aún, en la mejora de los sistemas de difusión y venta de sus frutos.

TABla 2. Distribución Regional del regadío (2008)

\begin{tabular}{lrrrrc} 
Comunidades & \multicolumn{1}{c}{ Has } & \% regional & \% gravedad & $\%$ aspersión & $\%$ otras \\
\hline Andalucía & & & & & \\
Aragón & 892.044 & 18,04 & 42,3 & 21,1 & 36,6 \\
Asturias & 443.592 & 17,81 & 80,5 & $17 ., 4$ & 2,2 \\
Baleares & 3.747 & 1,13 & 48,7 & 51,3 & - \\
Canarias & 20.788 & 10,75 & 25,2 & 57,5 & 18,3 \\
Cantabria & 23.667 & 31,51 & 15,7 & 19,1 & 65,3 \\
Castilla y León & 1.346 & 0,79 & 11,0 & 89,0 & - \\
Castilla-La Mancha & 562.189 & 10,52 & 61,2 & 38,7 & - \\
Cataluña & 470.882 & 9,94 & 32,0 & 55,3 & 12,7 \\
C. Valenciana & 269.285 & 22,72 & 68,8 & 12,2 & 19,0 \\
Extremadura & 365.307 & 42,84 & 80,2 & 0,9 & 18,9 \\
Galicia & 212.198 & 9,45 & 69,0 & 26,2 & 4,9 \\
Madrid & 58.102 & 6,91 & 64,4 & 35,6 & - \\
La Rioja & 32.274 & 8,75 & 86,1 & 13,9 & 0,7 \\
Murcia & 44,28 & 16,31 & 66,0 & 28,8 & 5,2 \\
Navarra & 190.689 & 30,63 & 60,3 & 3,0 & 36,8 \\
País Vasco & 87.243 & 14,16 & 89,2 & 9,8 & 1,1 \\
España & 10.906 & 4,47 & 10,1 & 89,6 & 0,3 \\
& 3.688 .587 & 14,45 & 59,2 & 23,9 & 16,8 \\
\hline
\end{tabular}

Fuente: MAPA. Plan Nacional de Regadío. Horizonte 2008. 


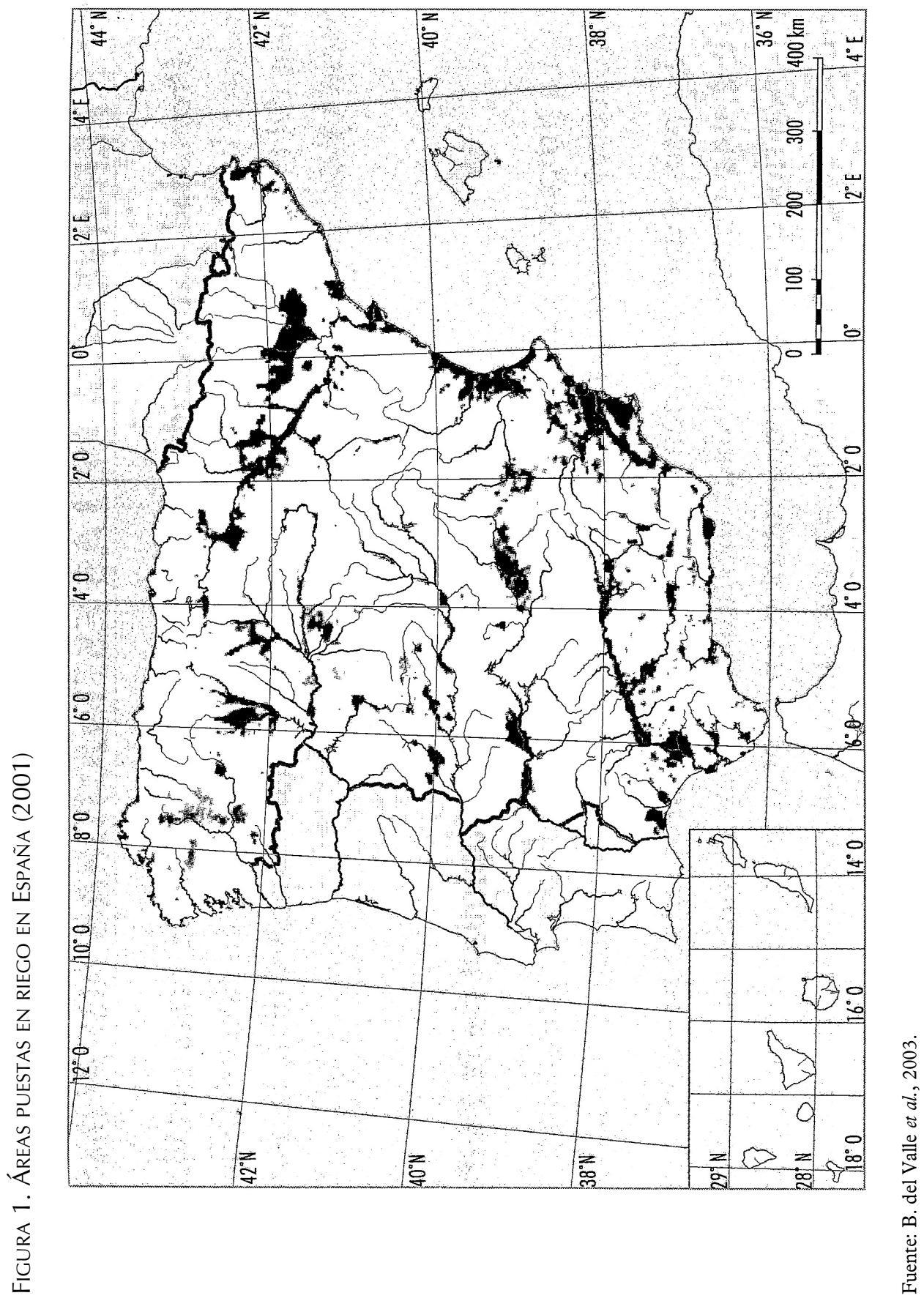


Un ejemplo significativo puede encontrarse en la importancia alcanzada por las diversas nuevas formas de riego dispersas con muchos matices por todas las regiones agrarias españolas, por ejemplo, los de "aspersión", los más generalizados, a los que cabe unir, con mucha menos implantación, el riego por "goteo" y las fórmulas "hidropónicas", entre otras modalidades más locales (tabla 2 y figura 1).

Modernización que no tiene la misma presencia en todos los regadíos regionales. Mientras que las innovaciones en el riego —en concreto, la aspersión - alcanza sus cimas en las regiones de máxima expansión reciente de la irrigación: Castilla-La Mancha, 260.397 ha de regadío por aspersión (55,3\%), Castilla y León, 217.567 ha (38,7\%), y Andalucía, 188.221 (21,1\%), las Huertas levantinas (C. Valenciana y Murcia), las de máximo desarrollo tradicional y más significado internacional hoy, sólo habían creado hasta el año 2000 en conjunto 9.373 ha, apenas el $2 \%$ de su regadío total, manteniendo sus añejos métodos, el riego por gravedad, presente en más del $80 \%$ de sus tierras irrigadas. Los planteamientos empresariales aparecen mucho más dispersos, teniendo una gran importancia, con viejo origen, en las Huertas de Valencia y Murcia, así como en los invernaderos almerienses, mucho más modernos.

A partir de los años setenta del siglo xx, el ritmo de la puesta en regadío se ha amortiguado, sobre todo por parte del Ministerio de Obras Públicas-Fomento. En cierta medida, por razones presupuestarias, pero también por haberse alcanzado un techo muy elevado en los costes y en las mismas posibilidades del medio físico y de las técnicas de creación de nuevos regadíos, y no menos por la intensidad alcanzada por los movimientos ecologistas, que cada vez más critican y se oponen, por razones de defensa del medio, a unas obras que, a menudo, implican no sólo la transformación del paisaje sino también su destrucción. Recuérdese la respuesta, a veces violenta, que, en los años ochenta, provocó la construcción de una de las últimas grandes obras públicas habidas, el embalse de Riaño, en la cuenca del río Porma, al norte de León y cerca del límite con Asturias.

Desde entonces la iniciativa privada ha ido acrecentando su peso. A partir de 1975 , entre el $50 \%$ y el $60 \%$ de la superficie transformada ha estado en cierta medida al margen de la promoción pública y ha respondido a muy concretos intereses privados con todos los riesgos y ventajas que pueden derivarse de ello. Sin embargo, en muchos de estos casos, no ha faltado el apoyo oficial a través de ayudas de muy diferente cariz y subvenciones públicas a fondo perdido y, más aún, a bajo interés. 
Así, el campo de la actuación privada se ha alejado especialmente de los grandes empeños que siguen proyectándose y realizándose por el Gobierno central aunque siempre en relación con las Comunidades Autónomas. $\mathrm{Y}$ en todos los casos conforme a las directrices, muy rígidas y severas, de la Unión Europea. Existe una excepción significativa: las obras hidráulicas con estricta finalidad hidroeléctrica siempre desarrolladas por las principales empresas privadas, aparte alguna pública en trance de privatización, que controlan la producción y el consumo de electricidad nacional. Sucede $-y$ ha sucedido - con algunas de las grandes centrales de los Arribes del Duero (Iberdrola), en conexión con Portugal, del Miño-Sil (Fenosa), de los afluentes pirenaicos del Ebro (Endesa) o del Júcar (Iberdrola).

En definitiva, hoy, la acción privada en el ámbito del regadío se limita a transformaciones de menor entidad y coste como la mejora de las redes de canales y acequias y la racionalización del uso del agua. Uno de sus objetivos casi exclusivo es el aprovechamiento de los acuíferos subterráneos, que, hasta 1995, ha activado más de 655.000 ha, una parte importante en La Mancha y responsable, parcialmente, de los problemas de subsistencia de los humedales de la región y, en concreto, de las Tablas de Daimiel y, en menor participación, de las Lagunas de Ruidera (C. Ferreras, 1996).

Esta tendencia liberalizadora y privatizadora, muy relacionada con el acelerado consumo derivado de los usos domésticos y turísticos fue apoyada y confirmada por el Libro Blanco del Agua avanzado a la opinión pública en 1999. Y que fue el punto de partida de los sucesivos Planes Hidrológicos Nacionales del paso al siglo XXI, en parte contrapuestos, aprobados sucesivamente por las Cortes en 2000 y 2004 y parcialmente derogado el primero con la puesta en acción del segundo.

La puesta en regadío de toda esa masa total de algo más de cuatro millones de ha en 2005 ha exigido la construcción de una colosal infraestructura que tiene su mejor expresión en los más de 300 embalses —un centenar son esencialmente de producción hidroeléctrica- existentes en las diez cuencas hidrográficas que se reparten el territorio nacional. Tenían en 2006 una capacidad de $53.252 \mathrm{hm}^{3}$, la mayor de Europa y entre ellos se encuentran algunas de las obras hidráulicas más destacadas del mundo por su tamaño y, sobre todo, por su avanzada tecnología. Por ejemplo, los nueve embalses con una capacidad superior a los mil hm³: dos (Almendra, 2.649 hm³, y Ricobayo, 1.184) en la cuenca del Duero, tres en el Tajo (Alcántara, 3.162 hm³, Buendía, 1.639, y Valdecañas, 1.418), y sólo uno en las siguientes cuencas, La Serena (3.219 hm) en el Guadiana, Alarcón (1.112), en el Júcar, y Mequinenza (1.534) en el Ebro (Anuario El País, 2005). 
La riqueza derivada del agua embalsada es evidente. Aunque existen también ciertos hechos de orden físico dignos de consideración y, hasta cierto punto, contrapuestos a la buena marcha de la irrigación. Si las "avenidas" catastróficas del conjunto de los ríos españoles, especialmente los mediterráneos, han sido un hecho casi normal en la historia española, manteniendo aún cierta frecuencia, la construcción de los embalses de cabecera e, incluso, los de curso medio, ha facilitado la regulación del ritmo anual de los caudales fluviales y ha reducido notoriamente sus "crecidas" a menudo tan peligrosas. Por ejemplo, la que en 1982 destruyó la presa de Tous en el río Júcar y causó cuantiosos daños materiales en la villa de Alcira y en la misma ciudad de Valencia y las que, en las primaveras de 2007 y 2008, anegó las márgenes del Ebro medio destruyendo sus cosechas e, incluso, pusieron en peligro las obras en su realización final de la Exposición Internacional dedicada al Agua a celebrar durante el verano de 2008 en la capital aragonesa (AA. VV., 2006; Diario El País, 2007).

La regulación fluvial tiene como primera consecuencia la acumulación paulatina en dichos vasos de los derrubios arrastrados por la erosión de las aguas de escorrentía y de las mismas corrientes fluviales, sedimentación que con el tiempo puede llegar a colmatar los embalses y hacerlos inútiles. Así sucedió, primero, con los pantanos de Puentes y Valdeinfierno, construidos en el siglo XVIII en la cuenca del Guadalentín, y ha seguido ocurriendo posteriormente en algunos de los embalses más tempranos realizados en los afluentes pirenaicos del Ebro, por ejemplo, Lanuza y La Peña en el Gállego. Un hecho que sólo puede contener aunque sea parcialmente una política de reforestación general y, más en concreto, de las mismas cuencas afectadas y una adecuación de las presas y los embalses al aterramiento que facilite la evacuación de los sedimentos.

Esta acumulación de una parte sustancial de los derrubios aguas arriba, ha favorecido el incremento de la erosión fluvial en los cursos medios e inferiores y provocado la disminución de los aportes sedimentarios en la desembocadura. Un hecho que afecta especialmente a los deltas mediterráneos y provoca, incluso, el retroceso de la misma línea de costa, ya muy azotada por el oleaje y las mareas. Los deltas del Llobregat y del Ebro que avanzaban a razón de uno y diez metros respectivamente en los años cuarenta y cincuenta, ahora retroceden notoriamente tras la inauguración de los varios embalses del Ebro y sus afluentes — Reinosa, Yesa, Mediano, CaneIles, Mequinenza-, a un ritmo bastante acentuado y con peligro de pérdida de sus valores ambientales más significativos (A. López Gómez, 1983; A. Espanya Forcadell, 1996). 
En el conjunto del nuevo regadío español, quizá sea el Trasvase TajoSegura (1969-1979) la obra no sólo más ambiciosa política y tecnológicamente, y por ello, quizá, la mas debatida, sino también la que más ha modificado el territorio y, por tanto, el medio ambiente en el conjunto del territorio español. Un proyecto que tuvo precedentes varios a finales de la Edad Media y a lo largo de la Moderna, aunque limitados al intercambio de las aguas entre los mismos ríos regionales siempre acuciados por la escasez de agua del conjunto del Sudeste español (Alicante, Murcia y Almería), cuyas ventajas agrarias se habían reconocido siempre. Un antecedente más ambicioso, no realizado, que planteaba conducir caudales entre dos cuencas distintas, fue el trasvase de los ríos Castril y Guardal, dos afluentes del Genil y el Guadalquivir, a los campos murcianos del Segura durante el reinado de Carlos III y que pretendía construir un canal que condujese las grandes maderadas desde los pinares del complejo Segura-Cazorla-La Sagra hasta el arsenal de Cartagena para convertirlas en los palos maestros de los navíos de la marina española (A. Morales et al., 2005 y J. Mor de Fuentes y M. Alvar, 1952).

El actual trasvase se proyectó, como parte esencial de la política hidráulica del Franquismo, a partir de los principios teóricos del Plan Nacional de Obras Hidráulicas de Manuel Lorenzo Pardo de 1933, tendente a resolver el "desequilibrio hidráulico nacional" entre el Mediterráneo, la parte española más árida pero con más posibilidades agrícolas respecto a los mercados mundiales, y el Atlántico, con menos problemas de agua y más próximo agrícolamente al resto de Europa (F. López Bermúdez, 1969 y A. Morales Gil et al., 2005).

Básicamente el trasvase consiste en sangrar el Alto Tajo en el embalse de Bolarque (35 hm³) (Guadalajara), aguas debajo de los hiperpantanos de cabecera Entrepeñas $\left(804 \mathrm{hm}^{3}\right)$ y Buendía $\left(1.638 \mathrm{hm}^{3}\right)$ para conducir sus caudales mediante un túnel de unos 75 kilómetros de longitud hasta el pantano de Alarcón $\left(1.111 \mathrm{hm}^{3}\right)$ (Cuenca), en el río Júcar. Desde allí, por el canal del Talave, de 60 kilómetros, el agua llega, a través de la provincia de Albacete, a la cuenca del Segura. En total, una conducción de 286 kilómetros de longitud y $33 \mathrm{~m} 3 / \mathrm{s}$, que ha asegurado el riego tradicional de 46.816 ha deficitarias de las Huertas del Sudeste y conseguido la transformación en regadío de otras 90.000, es decir, un total de 136.816 ha de las provincias Murcia, Alicante y Almería, casi la totalidad de la superficie prevista, 138.816, hoy el espacio irrigado "de mayor rendimiento económico y social de España" (A. Morales et al., 2005, pág. 106). A su paso por la Mancha, la existencia del trasvase ha favorecido un regadío complementario, hasta cierto punto no formalizado y en parte sostenido por la utilización de las aguas subálveas, que se estima en unas 30.000 ha (A. Pillet, 2001) (figura 2). 


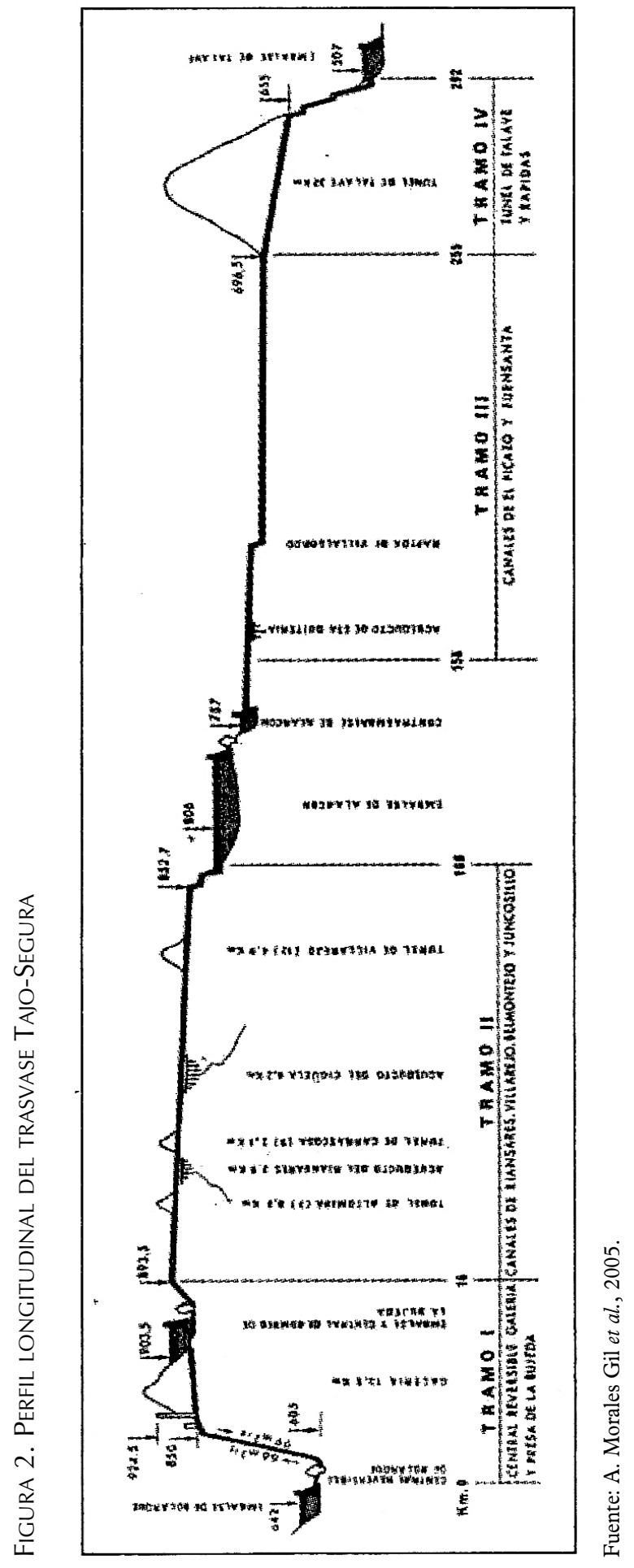


Además, el trasvase abastece a la industria, el turismo y el consumo de agua potable de las principales ciudades alicantinas y murcianas: aproximadamente, una población de 2,5 millones de habitantes. Un hecho este que no aparecía en los primitivos planes de los años treinta, que se introdujo en el proyecto de los sesenta y que, por el desarrollo, sobre todo turístico, de la costa alicantino-murciana, ha provocado en muchos momentos que se haya rebasado el volumen del caudal inicial previsto convirtiéndose en uno de los objetivos básicos de las posibles mejoras del trasvase. Incluso, se está utilizando como justificación en los recientes planteamientos de nuevos caudales procedentes del río Ebro. No menos contradictorio ha sido el frecuente incumplimiento del volumen previsto de agua trasvasada, como resultado de las alternativas anuales y estacionales de los caudales del Tajo y que han provocado que los mil hectómetros ofertados se hayan reducido a la mitad y, en los años secos, tan abundantes en el Sueste, a la tercera parte o menos. Un incumplimiento convertido en una servidumbre a considerar en todo trasvase planteado en el ámbito mediterráneo.

Por su parte, los usuarios del trasvase satisfacen a las regiones cedentes un canon de compensación territorial recogido en el concepto "a" del precio del agua recibida. La Ley de 1971 incluía en la tarifa el coste de las obras, los gastos fijos de mantenimiento y los costos variables del funcionamiento. La recaudación obtenida por el coste de las obras se destinaría preferentemente a la realización de determinadas obras hidráulicas en la cuenca del Tajo con independencia de los créditos consignados en los Presupuestos Generales del Estado. Por ejemplo, durante el año hidrológico 1995-1996, por una transferencia efectiva de 312 hm³, los usuarios del trasvase pagaron 1.972 millones de pesetas, a distribuir para esas obras entre Castilla-La Mancha (4/9), Madrid (3/9) y Extremadura (2/9). Igualmente, la Comunidad castellano-manchega ha visto aumentadas sus áreas de uso con demandas ambientales (Tablas de Daimiel) y urbanas, a unos cincuenta municipios, sobre todo del a provincia de Albacete (A. Morales et al., 2005, pág. 95; C. Ferreras Chasco, 1996). Todo ello no ha impedido sino todo lo contrario, un constante y siempre molesto debate entre la región cedente y las receptoras.

Con posterioridad, pese a las limitaciones legales existentes, en las últimas décadas del siglo XX y primeros años de 2000, se han producido algunos trasvases entre cuencas muy próximas y un muy limitado volumen de agua transferida. En 1982 entre el Ebro y el Besaya (Cantabria) y el Ebro y Bilbao, en 1989 entre el Ebro y Tarragona, en 2002 entre el Negratín, afluente del 
Guadalquivir, y el Almanzora, río perteneciente a la vertiente sur mediterránea, en 2004 del Tajo al Guadiana, en 2007 del Júcar al Vinalopó, previsto en el Plan Hidrológico de 2004, y en 2008 del Guadiana al Guadalquivir, todavía sin haberse iniciado. $Y$, en principio, con pagos importantes de la región beneficiada a los regantes propietarios del agua que, en definitiva, han vendido su agua, y permitido el trasvase. En el caso del Consorcio de Aguas de Tarragona, los pagos a los agricultores del Ebro han ascendido a un total de más de 43 millones de euros entre 1989 y 2008.

\section{Problemas estructurales CLIMÁticos, HidROLÓGICOS Y HUMANOS}

Hoy es evidente que el agua como recurso imprescindible en la existencia de la humanidad está en relación íntima con el medio ambiente. Si, por un lado, el agua cubre las tres cuartas partes de la superficie terrestre, de los 1.400 millones de $\mathrm{km}^{3}$ que constituyen la Hidrosfera, la capa líquida que cubre la Tierra, sólo un 3\% es agua dulce, frente a un $97 \%$ de agua salada. Incluso, de ese 3\%, nada más una tercera parte (1\%) corresponde a las aguas que, en forma de ríos, lagos u cursos subterráneos, discurre por la Troposfera, la capa sólida que emerge de los océanos, ya que el resto (2\%) está congelado en glaciares de montaña y casquetes polares.

Por otra parte, ese $1 \%$ de las aguas terrestres está muy mal repartido espacialmente, existiendo una serie de desiertos naturales y humanos, unos a lo largo de los Trópicos (Sahara, Próximo Oriente, noroeste del Indostán, suroeste de Estados Unidos y noroeste de México, suroeste de África, norte de Chile) y otros, continentales (centro de Eurasia), de máxima escasez, con lluvias escasas, menos de 250-100 litros por $\mathrm{m}^{2}$ y, por ello, con absoluta falta de cursos de agua superficiales exorreicos, algunas áreas de circulación temporal endorreica y un máximo riesgo de escasez y total falta del líquido elemento. A ello se une una lamentable mala gestión de su uso causa de que el consumo en el conjunto de los hogares de todo el mundo presente una tremenda e injusta desigualdad. Mientras en los Estados Unidos y Europa, el consumo por habitante y día oscila entre 300 y 600 litros, en Asia y Latinoamérica se mueve entre 50 y 100 y en África es inferior a 40 y, a menudo, no llega ni a diez. En el caso de los grandes consumidores, los países del mundo desarrollado, el precio del agua es, casi siempre, inferior a su coste real, un hecho que está conduciendo a que ya las Naciones Unidas y la Unión Europea estén planteando la obligación de que el coste del 
agua potable sea, como mínimo, cubierto por los consumidores, lo que, en el caso de España, obligaría a elevar ese precio en un $15 \% / 25 \%$ al menos (R. Méndez, 2007).

En fin, como colofón cabe recordar que, según el Consejo Mundial del Agua, actualmente un $20 \%$ de la población mundial no tiene acceso al agua potable, existiendo el riesgo de que, en 2025, debido a su incremento natural, ese porcentaje pudiera haber aumentado al 50\%. Incluso, el Foro del Agua afirma que el ritmo del consumo, sobre todo de los países desarrollados, es insostenible y debiera ser detenido y disminuido mediante una política inteligente de ahorro y mejor gestión del uso del agua. Y no sólo en la agricultura sino también en el consumo urbano tanto privado como público (R. Méndez, 2003).

En España, los condicionamientos naturales, como en todos los países mediterráneos, tienen considerable importancia en la existencia y el consumo del agua, con especial incidencia en el desarrollo de la agricultura, su principal usuario, no menos del $75 \%$ frente al uso doméstico, inferior al $10 \%$. Y, que tiene una gran repercusión en el característico desequilibrio espacial y temporal del territorio nacional. Un desequilibrio que se acentúa según los términos del clima peninsular y, sobre todo, de la variable pluviosidad interanual y la típica sequía estival propias de los países mediterráneos. Y que es el fundamento de la bien definida contraposición entre las tan acertadamente Ilamadas en 1904 por el geógrafo francés Jean Brunhes: Iberia húmeda e Iberia seca.

La primera de estas dos Españas, la Iberia húmeda, apenas una cuarta parte del territorio, recibe, como mínimo y con escasa desigualdad interanual, entre 700 y 1.500 litros de lluvia al año. No tiene por ello una necesidad explícita de manipular el agua de sus corrientes fluviales y siendo muy secundario el uso y la existencia del riego. A la par, su ritmo térmico no rebasa los $14^{\circ}$ de media anual y sus valores extremos, en invierno, superan el $0^{\circ} y$, en verano, se mantienen en torno a los $30^{\circ}$. Por ello, sus caracteres agrarios son muy similares a los de la Europa occidental y atlántica.

Por su parte, la Iberia seca, las tres cuartas partes del espacio español, no supera los 700 litros por metro cuadrado al año, una cifra que puede variar considerablemente de un año a otro y que tiende a disminuir espacialmente de Noroeste a Sudeste, y que padece de forma generalizada una estricta sequedad durante sus meses estivales. Cabe señalar la excepción de algunos macizos montañosos del extremo oeste de las Cordilleras Béticas, inmediatos al estrecho de Gibraltar, que llegan a menudo a convertirse en los lugares más Iluviosos de la Península. Sin embargo, en esa España seca, incluso, las áreas litorales mediterráneas del Sudeste hispano, en torno al 
20\% del territorio, recuerdan, con sus apenas 250 litros anuales de lluvia por $\mathrm{m}^{2}$, a las regiones áridas, desérticas, del cercano norte de África.

Más contrastadas son, aún, sus temperaturas. El interior peninsular, la Meseta central, contrapone su invierno, con heladas durante un promedio de unos doscientos días, a un estío, con cifras extremas en torno a los $40^{\circ}$. Por su parte, el litoral mediterráneo supera netamente los $0^{\circ}$ en invierno y se acerca a los $35^{\circ}$ en verano, con una excepción, el Sudeste, que, con el Valle del Guadalquivir, cuenta con los máximos de días de sol anuales y llega a alcanzar y superar los $40^{\circ}$ en el estío.

Las consecuencias derivadas del comportamiento del medio físico peninsular son por ello muy diversas en cada una de las cuencas hidrográficas española resaltan en primer lugar el contraste entre las vertiente septentrional —Galicia y regiones cantábricas - y mediterránea, desde la frontera francesa al estrecho de Gibraltar. También existen matices no tan contrastados entre las varias cuencas hidrográficas atlánticas y mesetarias y los dos grandes emisarios de los valles exteriores a la Meseta, el Ebro, en el nordeste, y el Guadalquivir, en el sudoeste (tabla 3).

TABLA 3. RECURSOS HIDRÁULICOS

Cuencas Escorrentía $\mathrm{hm}^{3} \quad$ Flujo de base $\mathrm{hm}^{3} \quad$ Aportación $\mathrm{hm}^{3} \quad \mathrm{~m}^{3} / \mathrm{hab}$.

\begin{tabular}{lrrrr}
\hline Cuencas del norte & 32.276 & 4.100 & 43.376 & 6.579 \\
Pirineo Oriental & 2.300 & 250 & 2.550 & 500 \\
Ebro & 15.191 & 2.900 & 18.091 & 6.737 \\
Duero & 10.720 & 1.450 & 12.170 & 5.332 \\
Tajo & 7.985 & 2.000 & 9.985 & 1.884 \\
Guadiana & 4.360 & 500 & 4.860 & 3.069 \\
Guadalquivir & 6.934 & 1.100 & 8.034 & 1.871 \\
Cuencas del sur & 1.940 & 700 & 2.640 & 1.629 \\
Júcar & 1.866 & 1.700 & 3.566 & 991 \\
Segura & 450 & 600 & 1.050 & 846 \\
Islas Baleares & 210 & - & 210 & 1.150 \\
Islas Canarias & 355 & - & 355 & 689 \\
& & & & \\
\hline
\end{tabular}

Fuente: Ministerio de Fomento.

Las diferencias del aprovechamiento agrario son, por ello, manifiestas. Frente al carácter propio de un medio templado oceánico similar a la Europa occidental y una agricultura no necesitada del regadío, el espacio litoral mediterráneo en general y, más aún, el correspondiente a las Comunidades Valenciana y Murciana más las provincias andaluzas de Almería y Granada, padece una endémica escasez de agua y exige una irrigación que añade a sus cultivos forzados tempranos — verduras, hortalizas y frutales— 
similares a los del Oeste europeo, otros propios de ámbitos subtropicales y tropicales, agrios, caña de azúcar, cactáceas, plátanos, chirimoyos, aguacates. Toda una producción específica de consumo muy apetecido y vendido en el conjunto de la Unión Europea (C. de los Llanos, 1990).

Una producción fundamental en el comercio exterior español, pero que tiene que superar obstáculos naturales varios propios de sus caracteres climáticos e hidrológicos. En principio, y como fundamental, la característica irregularidad fluvial que enfrenta la Iberia seca y húmeda. Mientras el caudal de los ríos de la vertiente cantábrica, con una pluviosidad más continuada y superior a los 700 litros por $\mathrm{m}^{2}$, oscila a lo largo del año entre dos y quince, los mediterráneos, con menos de 500 litros de Iluvia torrencial, mal distribuidos y un estiaje profundo, pueden variar entre cinco y el infinito. Un desequilibrio que comparten los grandes ríos - Duero, Tajo y Guadiana- de la Meseta, cuya irregularidad oscila entre 5 y 15, aunque aumenta de norte a sur, siendo mayor en el Guadiana (15) que en el Duero (5). Y que diferencia a los ríos principales de las cuencas ibérica (Ebro, 3/4) y bética (Guadalquivir, 4/6) (V. Masachs Alavedra, 1954; A. Cabo Alonso, 1990) (figura 3).

Figura 3. BALANCE HÍDRICO DE LAS CUENCAS HIDROGRÁFICAS PENINSULARES

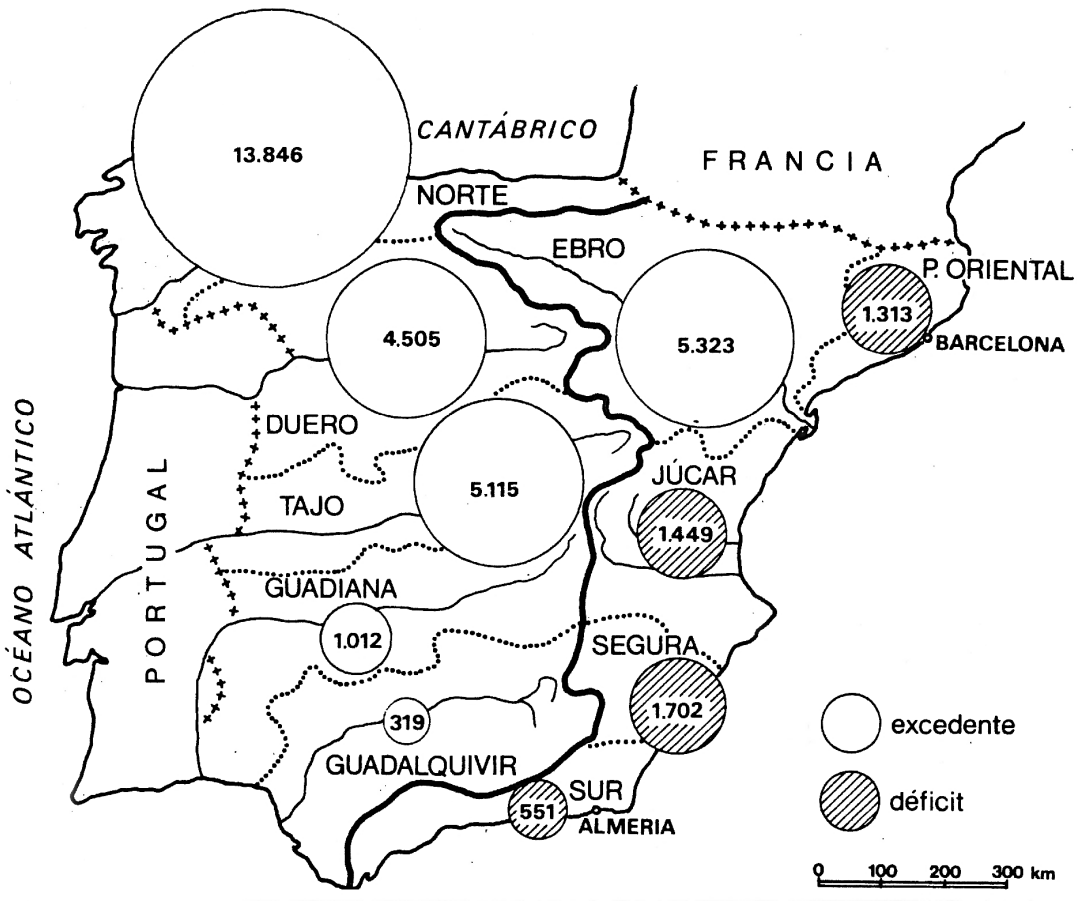

Fuente: M. de Terán y L. Solé Sabarís, 1994. 
Hay que añadir una contrapartida que acompaña de forma desigual a los diferentes regímenes de la red fluvial española, las "crecidas", inundaciones temporales, normales precisamente en el medio ambiente mediterráneo frente a su escasa frecuencia en las cuencas de la Iberia húmeda y a una situación intermedia, que varía de Norte a Sur, en los grandes ríos de la Meseta y tiende a igualar la caudalosidad del Ebro y el Guadalquivir. Una consecuencia resultante de esta irregularidad del ritmo fluvial es la diversa y, en cierta forma limitada, capacidad de crear una reserva de agua suficiente para atender las necesidades de la población y la economía españolas.

No obstante, la política hidráulica de los últimos cien años ha sido capaz de crear una reserva total considerable calculada en el año 2006 en $53.252 \mathrm{hm}^{3}$ pero tan desigualmente repartida que mientras toda la Hispania atlántica alcanza un superávit de $24.797 \mathrm{hm}^{3}$ anuales, con su volumen máximo en su vertiente norte (gallego-cantábrica) con un total de 13.846 $\mathrm{hm}^{3}$ (55,9\%), el territorio que aboca al Mediterráneo, salvo el Ebro, con un superávit calculado en $5.323 \mathrm{hm}^{3}$, tiene un déficit mínimo de $5.015 \mathrm{hm}^{3}$, de los cuales 1.313 pertenecen a la vertiente catalana dependiente del Pirineo Oriental, 1.449 a la cuenca del Júcar, 2.702 a la del Segura y 551 a la sur mediterránea. Una realidad que ofrece variantes sensibles si se consideran a cada una de las cuencas hidrográficas existentes ( $M$. de Terán y L. Solé Sabarís, 1994) (tabla 4).

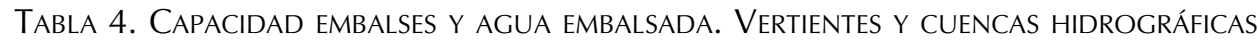
(1995-2006)

\begin{tabular}{|c|c|c|c|c|}
\hline Vertientes & Capacidad máxima hm³ & Media $1995-2005 \%$ & $\% 2006$ & $\% 2005$ \\
\hline Cantábrica & 647 & 76,5 & 71,4 & 75,3 \\
\hline Galicia & 3.714 & 70,0 & 70,9 & 61,5 \\
\hline Duero & 7.463 & 67,3 & 60,5 & 51,2 \\
\hline Tajo & 11.009 & 60,1 & 49,3 & 40,3 \\
\hline Guadiana & 8.859 & 70,2 & 54,1 & 59,4 \\
\hline Guadalquivir & 8.801 & 66,6 & 38,9 & 51,3 \\
\hline Atlántica & 38.797 & 65,6 & 52,5 & 52,4 \\
\hline Sur mediterránea & 1.041 & 52,2 & 32,9 & 38,0 \\
\hline Segura & 3.290 & 24,1 & 14,7 & 14,7 \\
\hline Júcar/Turia & 3.346 & 31,1 & 17,5 & 25,7 \\
\hline Ebro & 6.504 & 74,3 & 55,9 & 60,4 \\
\hline Cataluña & 740 & 59,7 & 65,9 & 35,0 \\
\hline Mediterránea & 12.760 & 56,3 & 40,9 & 43,9 \\
\hline Total & 53.252 & 56,3 & 49,7 & 50,3 \\
\hline
\end{tabular}

Fuente: Ministerio de Medio Ambiente, 2005. 
Se ha calculado que la máxima capacidad —medida en $\mathrm{hm}^{3}$ del caudal total recibido - de los embalses españoles existentes en el conjunto de las cuatro vertientes peninsulares - Cantábrica, Atlántica, Sur Mediterránea y Mediterránea- era de $53.252 \mathrm{hm}^{3}$ en el año 2006. Una cifra que es el resultado de una política de creciente creación de pantanos artificiales y sus correspondientes redes de regadío. En 1970 se limitaba a un total de 30.422 hm³, en 1980, a 40.524, en 1990, a 48.692 y a 49.100 en 2000.

Sin embargo, como corresponde a un medio físico como el hispano, las diferencias de agua embalsadas pueden variar mucho de un año a otro $y$, no menos, en el transcurso del año en el que la sequía estival juega un papel muy importante. Así, la capacidad máxima media durante el decenio 19701980 osciló en torno a un $65 \%$ del total posible, 40.524 hm³, mientras que en el periodo 1995-2005 se limitó a 29.981 hm³, el 56,3\%. La media mayor de agua embalsada se vio confirmada en el primer decenio por su concentración de hasta seis años hidráulicos por encima del 50\%, mientras que en el segundo sólo en tres ocasiones, en tres años, se llegó a ese porcentaje. Los mayores valores anuales se produjeron en los años hidráulico 1970-71, con un máximo del 62,1\%, 1980-81, 65,5, 1987-88, 70,6, 1985-86, 65,0, y 1990-91, 62,2, mientras que los mínimos tuvieron lugar en 1981, 40,4\%, 1993-94, 33,8, 1994-95, 26,0, y 2005-2006, 39,4.

De aquí los fuertes contrastes existentes de agua embalsada, siempre menor en verano, entre las dos grandes vertientes peninsulares como también entre las diversas cuencas fluviales tanto atlánticas como mediterráneas. Mientras la media de los últimos diez años (1995-2005) en la vertiente atlántica ha sido de un $65,6 \%$, en los ríos mediterráneos, sin el Ebro, no ha rebasado el $40 \%$. Y como casos extremos, si el Miño ha llegado como promedio a una reserva superior al $75 \%$, el Segura se ha limitado a sólo un mínimo del $24,1 \%$. Y no cabe olvidar que las diferencias interanuales en las reservas de agua pueden ser aún mayores: así, las correspondientes a la vertiente atlántica fueron el año 2001-2002 de un $64,8 \%$ y en $2004-2005$ de un 52,4 , mientras en la mediterránea, se limitaron a un 40,0 (2001-2002) y a un 35,1 (2004-2005), y en el conjunto peninsular, oscilaron entre el 62,2 y el 43,6 (INE, 2005).

En los desequilibrios existentes en los caudales y las reservas de agua es evidente que los condicionamientos del medio físico — en concreto, la pluviosidad - juegan un papel importante. Sin embargo, tampoco cabe duda que las técnicas que dieron lugar a las infraestructuras que permiten el almacenamiento y el uso del agua tienen una considerable importancia. Un hecho que se percibe claramente en las mermas sufridas tanto en los embalses como a lo 
largo de sus diversas conducciones - canales y acequias - a causa de los fallos estructurales, como la falta de recubrimientos impermeables y de su construcción al aire libre, fallos que provocan filtraciones y evaporaciones que, en conjunto, significaron en 2005 unas pérdidas totales de 927.43 hm $^{3}$ (19,4\%) del agua embalsada $\left(4.785 .15 \mathrm{hm}^{3}\right)$ en uno de sus periodos de mínimos y que, en determinados momentos, pueden ser mucho mayores (tabla 5) (figura 4).

Unas pérdidas muy diferentes según los casos, por su situación en distintos espacios climáticos, y también a causa de la distancia a recorrer por el agua o por el modelo de construcción de las distantes partes de la red de distribución. Así, las regiones mediterráneas, porción esencial de la España seca, son las que más pierden —Aragón, 24,6\%, la Comunidad Valenciana, 26,3, y Murcia, 30,0-, superando netamente la media nacional de la pérdida de agua calculada en 927,43 hm³ $^{3}$ el $19,4 \%$, en 2005 . En cambio, las comunidades propias de la España húmeda se alejan bastante del promedio: Navarra, 12,3\%, La Rioja, 14,6, Extremadura, 16,0, Galicia, 16,2.

Figura 4. Pérdidas de agua en la Red de distribución del ReGadío español (Según el Ministerio de Fomento y anuario El País (2007)

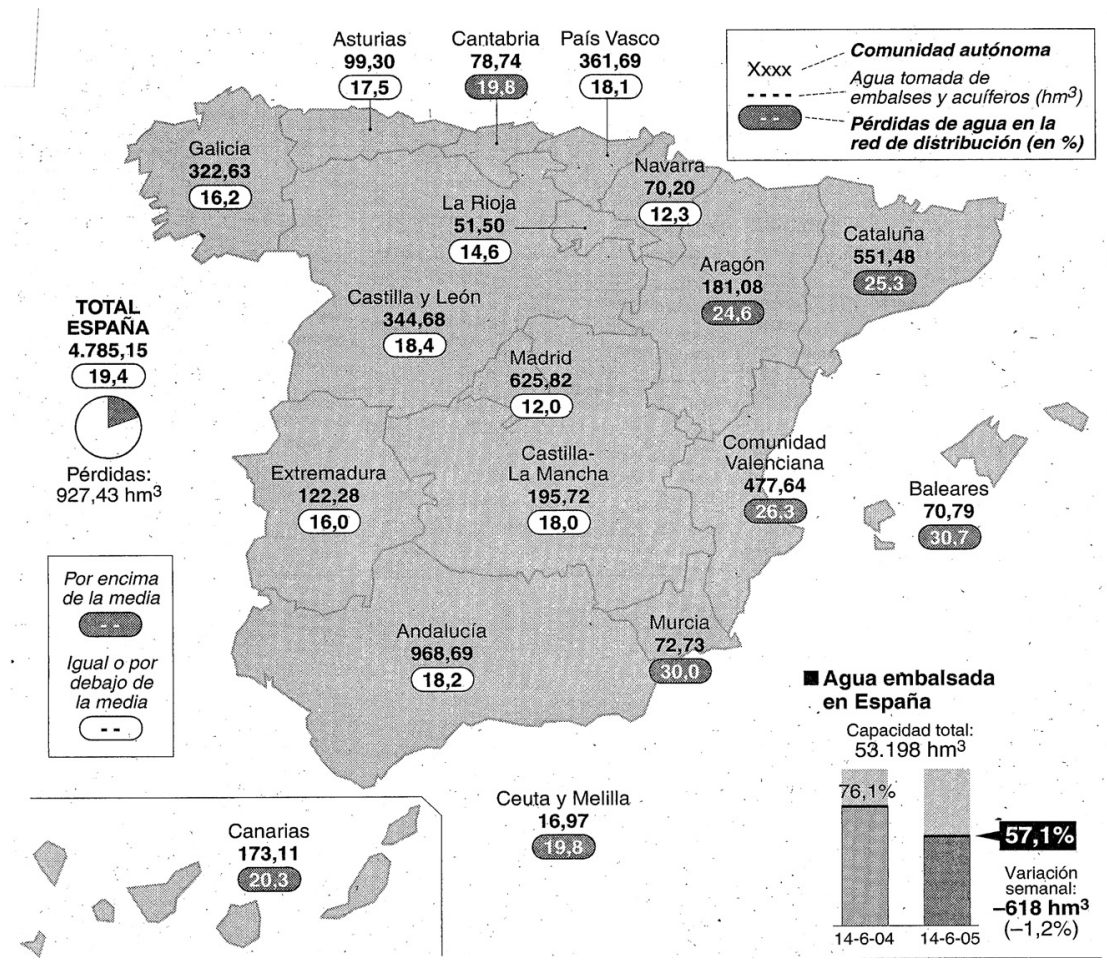


Un elemento a añadir a estas mermas, es la mayor o menor racionalidad en los usos del agua. Los resultados son muy diferentes en el riego por gravedad, "a manta", con grandes pérdidas por filtración y evaporación, que es mayoritario en los regadíos valencianos y murcianos, que en los procedimientos más eficientes, los riegos por "aspersión" y "a goteo", entre otros más locales, muy extendidos en Asturias, Baleares, Castilla-La Mancha y Andalucía) (tabla 2).

Tabla 5. Pérdidas de agua en la Red de distribución por Comunidades (2005)

\begin{tabular}{lrr} 
& $\begin{array}{c}\text { Agua embalsada } \\
\mathrm{hm}^{3}\end{array}$ & \multicolumn{1}{c}{$\begin{array}{c}\text { Pérdidas de agua } \\
\%\end{array}$} \\
\hline Andalucía & 968,69 & $18,2\left(175,5 \mathrm{hm}^{3}\right)$ \\
Aragón & 181,08 & $24,6\left(44,5 \mathrm{hm}^{3}\right)$ \\
Asturias & 99,30 & $17,5\left(17,4 \mathrm{hm}^{3}\right)$ \\
Baleares & 70,79 & $30,7\left(21,8 \mathrm{hm}^{3}\right)$ \\
Canarias & 173,11 & $20,3\left(96,1 \mathrm{hm}^{3}\right)$ \\
Cantabria & 78,74 & $19,8\left(15,5 \mathrm{hm}^{3}\right)$ \\
Castilla y León & 344,68 & $18,4\left(63,5 \mathrm{hm}^{3}\right)$ \\
Castilla-La Mancha & 195.72 & $18,0\left(35,2 \mathrm{hm}^{3}\right)$ \\
Cataluña & 651,48 & $25,3\left(139,8 \mathrm{hm}^{3}\right)$ \\
C. Valenciana & 477,64 & $26,3\left(123,4 \mathrm{hm}^{3}\right)$ \\
Extremadura & 122,28 & $16,0\left(19,5 \mathrm{hm}^{3}\right)$ \\
Galicia & 322,63 & $16,2\left(52,3 \mathrm{hm}^{3}\right)$ \\
La Rioja & 51,50 & $14,6\left(7,6 \mathrm{hm}^{3}\right)$ \\
Madrid & 625,82 & $12,0\left(65,6 \mathrm{hm}^{3}\right)$ \\
Murcia & 72,73 & $30,0\left(21,9 \mathrm{hm}^{3}\right)$ \\
Navarra & 70,20 & $12,3\left(8,6 \mathrm{hm}^{3}\right)$ \\
País Vasco & 361,69 & $19,1\left(69,2 \mathrm{hm}^{3}\right)$ \\
Ceuta y Melilla & 16,91 & $19,8\left(3,3 \mathrm{hm}^{3}\right)$ \\
Total España & $4.785,15$ & $19,4\left(327,43 \mathrm{hm}^{3}\right)$ \\
\hline Fuente: Ministion & &
\end{tabular}

Fuente: Ministerio de Fomento.

Otro hecho a considerar es el limitado reciclado de las aguas ya usadas y, por ello, sin nuevo uso posible, de muchas de las áreas urbanas y de la mayor parte de los núcleos rurales. En 2004, un Informe de la Unión Europea calculaba que en España existían 70 ciudades de más de 15.000 habitantes que no cumplían el tratamiento de las aguas residuales, situando a nuestro país a la cabeza entre los infractores medioambientales de la UE que, en consecuencia, decidió abrir un expediente por ese y otros incumplimientos (G. Cañas y B. Lucas, 2004).

Greenpeace denunció poco después, en el año 2005, una situación muy alarmante en las poblaciones costeras ya que el $41 \%$ de los 363 municipios estudiados no trataban sus aguas residuales y las vertían directamente 
al mar. Una situación que la explosión constructora de los últimos años no ha solucionado sino todo lo contrario. Últimamente, en los años del boom de la construcción no se ha producido una acción paralela de las medidas depuradoras imprescindibles exigidas legalmente. A comienzos de 2007, según el Ministerio del Medio Ambiente, ochocientos núcleos urbanos de más de 2.000 habitantes que suman unos 6,5 millones de personas, entre ellos Badajoz (143.748), Burgos (173.600), A Coruña (243.000), Ciudad Real (70.124), Melilla (68.900) Ourense (109.000) y Oviedo (214.880), todos ellos capitales de provincia, no depuran, o lo hacen insuficientemente, sus aguas residuales (L. Galán, 2007).

Tal situación ha provocado la promulgación en el año 2007 de un nuevo Plan de Saneamiento y Depuración que invertirá hasta 2015 en 2.072 actuaciones 19.700 millones de euros en resolver los problemas de depuración existentes actualmente y también prevenir los que puedan tener lugar en un futuro próximo. Su financiación incrementará el precio del agua en un 30\% que, como exige la Directiva de la Unión Europea Marco del Agua deberá repercutirse en los usuarios. El precio del agua en España es de los más baratos de Europa.

\section{La Ley del Agua, el Plan Hidrológico Nacional Y EL TRASVASE DEL EBRO (2000-2008)}

El desequilibrio hidráulico nacional, con sus consecuencias lógicas de difícil abastecimiento de agua para el riego y las restantes necesidades industriales, turísticas y atención humana se ha complicado notoriamente en los últimos decenios del siglo XX y primeros años del XXI. Se trata de un hecho notorio que alcanza sus términos menos favorables, especialmente, en las Comunidades del Levante español y en las provincias andaluces más orientales, una porción importante del espacio español por su dinamismo socioeconómico y un creciente incremento del consumo de agua a todos los niveles.

En paralelo, como ya se ha señalado, se tropezaba con las ya escasas posibilidades de creación de nuevos aprovechamientos hidráulicos según el sistema tradicional de "presas y embalses" y, también, a los limitados avances en un uso más racional y menos costoso ambiental y económicamente de las reservas de agua. Todo ello parecía conducir inevitablemente, según algunas regiones, a un nuevo y definitivo trasvase entre las comunidades con isobrantes? y aquellas otras con urgentes e inmediatas necesidades y 
¿cesiones? conforme a la vieja solución de Manuel Lorenzo Pardo de 1933. Es claro que también no cabía olvidar las nuevas circunstancias en que vivía y se movía la sociedad española del III Milenio. Y que se estaba planteando el hecho ya admitido de que "el agua es un recurso escaso y finito".

La problemática del agua existente tradicionalmente en España, como en el resto del mundo mediterráneo, había adquirido a lo largo del siglo XX nuevos matices. A comienzos de los años setenta se plantearon, a causa de los problemas de abastecimiento del área metropolitana barcelonesa, posibles trasvases desde el Ebrio y desde el Ródano, provocando un duro enfrentamiento entre las opiniones públicas aragonesa y catalana, Ilegándose a hablar de una "batalla por el Ebro". No se pasó de la discusión periodística y no se llegó a ningún planteamiento oficial (E. Barrenechea, 1974).

No obstante, el problema del agua existía y exigía, sin duda, soluciones novedosas y también una revisión profunda de las numerosas medidas prácticas y administrativas tradicionales que habían culminado en la Ley de Aguas de 1879. Así, el tema, tras más de un siglo de vigencia, condujo a una revisión de todo el conjunto de tales disposiciones y provocó diversas actuaciones políticas y sociales origen de una nueva Ley de Aguas, fruto de un gobierno socialista presidido por Felipe González y aprobada por el Parlamento español en 1985 (A. Menéndez Resach; J. M. Díaz Lema, 1986).

En estas nuevas circunstancias legales, la búsqueda de una solución parecía obligada. En 1993, el Ministerio de Obras Públicas del último gabinete socialista de Felipe González presentó un Plan Hidrológico Nacional que incluía por primera vez un posible trasvase del Ebro. Tuvo lugar entonces un tenso debate en el que no sólo la oposición, el Partido Popular sobre todo, combatió sus líneas básicas, sino también algunos gobiernos comunitarios del PSOE, como la Junta de Comunidades de Castilla-La Mancha, objetaron aspectos concretos de esa propuesta, que no llegó a buen fin (MOPT, 1993).

Más tarde, ya en el poder (1996) el Partido Popular, fueron varios los borradores sometidos a consideración y que, en primer lugar, dieron lugar a la publicación en 1999 por el Ministerio de Medio Ambiente de un Libro Blanco del Agua. En este documento se hacía una estimación de las posibilidades y características del agua en el país y de las reservas existentes susceptibles de ser trasvasados entre determinadas cuencas hidrográficas y capaces de corregir los desequilibrios hídricos vigentes, ya señalados en 1933 por Manuel Lorenzo Pardo. Con esta base, en el año 2000, se prepararon y presentaron, como actuaciones distintas pero con el mismo fin, un Plan Hidrológico Nacional y un Plan Nacional de Regadíos a realizar entre los años 2000-2008, 
que tras ser sometidos a un largo y bronco debate parlamentario y social, fueron aprobados sin consenso por las Cortes (2001).

Los objetivos del doble Plan 2000-2008 se cifraban, conforme a la mencionada Ley de Aguas, en "conseguir la mejor satisfacción de las demandas de agua y equilibrar y armonizar el desarrollo regional y sectorial, incrementando las disponibilidades del recurso, protegiendo su calidad, economizando su empleo y racionalizando sus usos en armonía con el medio ambiente y los demás recursos naturales" (art. 38.1 de la Ley de Aguas). En principio, pues, se trataba de resolver el problema del desequilibrio de caudales existente entre las diferentes vertientes y cuencas que constituyen la realidad hidrográfica española (tabla 3).

Una situación resuelta presuntamente mediante la invención de un triple conjunto de actuaciones, el Trasvase del Ebro y los Planes Hidrológico Nacional y Nacional de Regadíos 2000-2008 que, como los de Gasset y Lorenzo Pardo, de comienzos y mediados del siglo XX, pudieran superar con un uso más adecuado a las circunstancias físicas del momento y a las nuevas posibilidades tecnológicas un problema — "un agua escasa y finita" común, por otra parte, a todo Occidente pero que se acentuaba y agravaba en los países mediterráneos y, en particular, en España.

El conjunto de actuaciones previstas eran diversas. Por un lado, la más discutida —y discutible — era, no sólo la confirmación y ampliación del trasvase del Tajo sino, sobre todo, una nueva transferencia de caudales - $1.050 \mathrm{hm}^{3}$-, del Ebro a los ríos Júcar y Segura a fin de poder asegurar y ampliar los regadíos de Castellón, Valencia, Alicante y Murcia e, incluso, de Almería, y también atender las crecientes necesidades del consumo urbano y, en especial, del turístico de esas partes del arco mediterráneo español. Constituía, según la Introducción al PNH, la "infraestructura básica del Plan" y se justificaba por la "bancarrota hídrica" del sureste español que no entendía que "cientos de metros cúbicos (del Ebro) se viertan al mar". Asimismo, se añadían otras varias actuaciones ordenadas en dos conjuntos distintos aunque complementarios, el Plan Hidrológico Nacional y el Plan Nacional de Regadíos (PNR), ambos a realizar en el periodo 2000-2008.

En la presentación a información pública del trasvase del Ebro, el trazado final propuesto tenía una longitud de $914 \mathrm{~km}$, diferenciados en dos ramales —norte y sur - que tenían su origen común en Tortosa, a una altura próxima al del nivel del mar, y que divergían luego. El ramal septentrional, de $172 \mathrm{~km}$, nacía en Camp-Redó, y llegaba hasta Tarragona y Villafranca del Penedés (Planta de tratamiento de Abrera), y el meridional, desde Xerta, recorría 742 km, alcanzaba una altitud de casi 500 metros y terminaba en Aguadulce (Almería), 
pasando por Alcora, Villena, Lorca, Níjar y Almería. Su objetivo, trasvasar 190 $\mathrm{hm}^{3}$ al área metropolitana de Barcelona y distribuir otros 860 por todo el litoral mediterráneo hasta Aguadulce: en total $1.050 \mathrm{hm}^{3}$. Un recorrido final de $914 \mathrm{~km}$ cubierto por $332 \mathrm{~km}$ de canales, el 36\% a cielo abierto, 96 de túneles, 391 de tunerías, 83 de sifones, 12 de acueductos, 21 balsas de regulación y un embalse. Una obra presupuestada en 4.091,9 millones de pesetas, 246,5 millones de euros, extremadamente ambiciosa y de una gran complejidad técnica y un intenso y grave impacto ambiental (figura 5).

Figura 5. El trasvase del Ebro según la Presentación e Información Pública (2000) y EL DIARIO El PAÍS, 19 DE MARZO DE 2003

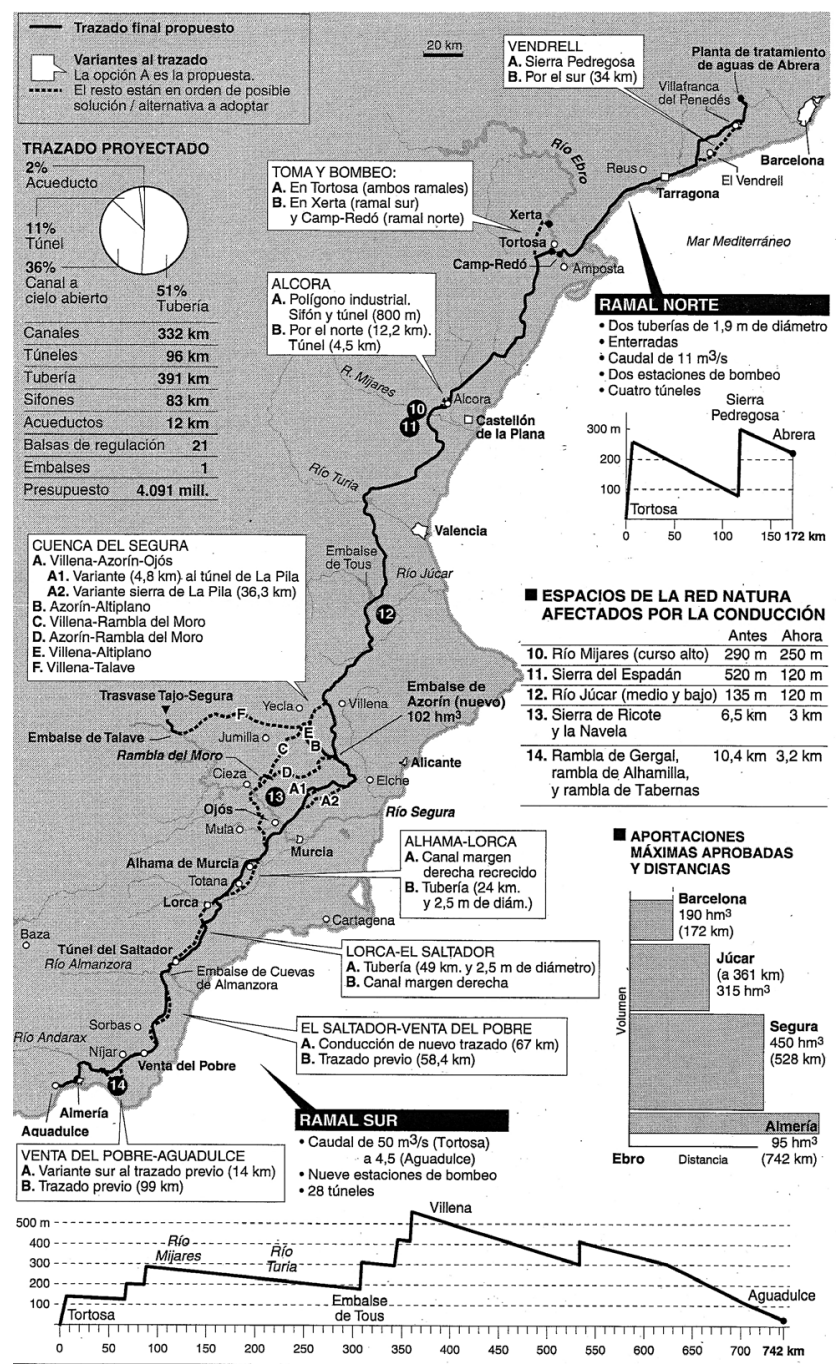


El Plan Hidrológico Nacional (PHN) 2000-2008 propuesto por el Ministerio del Medio Ambiente implicaba unas inversiones globales públicas y privadas en pesetas de 3.020 millones, unos 181,9 millones de euros. De esta cifra la mayor parte se destinaba a financiar las inversiones en mejora y modernización del regadío, a facilitar la gestión y ahorro de los recursos hídricos y a la renovación de las infraestructuras del riego (tabla 6).

Tabla 6. Actuaciones del Plan Hidrológico Nacional (PHN) 2000/2008

Presupuesto (millones ptas.)

$\%$ sobre total

Regulación de cuencas fluviales

Modernización de regadíos

501.718

958.594

16,61

Abastecimientos urbanos

408.996

31,74

Acondicionamiento de cauces y prevención de avenidas

227.497

14,17

Programa de control y calidad aguas

Regeneración hidrológico-forestal

208.497

7,54

286.717

6,90

Total

3.019 .720

9,50

100,00

Fuente: Ministerio de Medio Ambiente.

Por su parte, el Plan Nacional de Regadíos 2000-2008 pretendía actuar sobre las infraestructuras de los regadíos existentes con el fin de utilizar el agua de una forma más racional y mejorar la rentabilidad de las explotaciones y del nivel de vida de los agricultores y, también, ampliar el regadío actual en un total de 242.791 ha con rentabilidad técnico-económica e interés social. Para cumplir con esos propósitos el Ministerio de Agricultura (MAPA) preveía invertir un total de 837.405 millones de pesetas (5.042 millones de euros) a los que unirían otros 50.000 millones (301,2 millones de euros) a invertir por las Sociedades Estatales de Regadío. De la primera cifra, el $60 \%$ procedería del MAPA y de las Comunidades Autónomas y el resto sería proporcionado por la iniciativa privada.

No obstante, la batalla dialéctica habida en las Cortes no terminó con la corroboración y entrada en vigor del PNH 2000/08 en el año 2001, sino todo lo contrario. En el arco mediterráneo español se inició un duro debate a causa del agua, enfrentando a partidos políticos y comunidades autónomas por el trasvase del Ebro. En principio, el Partido Popular y las comunidades valenciana y murciana por él gobernadas consideraban inexcusable una transferencia que, en todos los Planes Hidrológicos desde el de Gasset, se había prometido y exigido. La oposición parlamentaria, con el PSOE a la cabeza, y las comunidades aragonesa y catalana estaban en contra. 
Se habían creado, se afirmaba, unas expectativas a partir de las cuales parecía que se habían hecho cálculos sobredimensionados de los posibles recursos hídricos a disposición del Levante. Previamente se habían puesto en regadío nuevos terrenos —unas 100.000 ha- que precisaban asegurar su mantenimiento con el agua por llegar y abierto más pozos, en su mayor parte, ilegales, de los admitidos por los caudales subterráneos existentes. En fin, parecía haberse llegado a superar agrícolamente no sólo las posibilidades limitadas del medio ambiente propio sino que a las necesidades imprescindibles del consumo público regional de agua potable se habían añadido las exigencias impuestas al máximo por el desarrollo del turismo, que ya había macizado y cementado casi todo el litoral valenciano y alicantino y, en parte, el murciano.

Y no hay que olvidar que el trasvase, un largo canal de 912 kilómetros preparado para conducir $1.050 \mathrm{hm}^{3}$ desde el delta del Ebro hasta enlazar con el Tajo/Segura, se completaba con la construcción de 112 nuevos embalses, 36 estaciones desaladoras y 242.791 ha de nuevos espacios regados. Además, se garantizaba la regulación de las cuencas fluviales, la modernización de los sistemas de riego, el acondicionamiento de cauces y la prevención de avenidas, la mejora y el control de la calidad de las aguas y la regeneración del espacio hidrológico forestal y a la consolidación y reforma de los regadíos ya existentes. Todo ello a realizar en ocho años (2000-2008).

Un programa que exigía un presupuesto total calculado en $7.948,41$ millones de pesetas, unos 500 millones de euros, en el que el coste del trasvase del Ebro, la obra mayor, sumaba 4.091 millones, y se completaba con los 3.020 millones del PHN y los 837.405 millones del PNE destinados a la creación de 242.791 ha de nuevos espacios regados. Unas elevadas cifras - casi ocho mil millones de pesetas, unos cincuenta millones de eurosque se confiaba fuesen subvencionadas parcialmente por la Unión Europea si se llegaban a cumplir determinados requisitos ambientales y tecnológicos por ella exigidos.

El Plan era rechazado, en concreto, en lo que se refería al transvase del Ebro y también en cuanto se discutían muchos de sus términos afines a la vigente cultura economicista del agua y el modelo vivo de "presa y trasvase". Por ello, en la oposición se encontraban todos aquellos que pretendían Ilegar a una Nueva Cultura del Agua que tuviese en cuenta los principios del desarrollo sostenible en un medio ambiente integral en el que el impacto sobre la naturaleza fuese mínimo (P. Arrojo Agudo, 1998 y 2005).

Entre los opuestos al trasvase estaban, en primer lugar, las comunidades autónomas aragonesa —300 de los 900 kilómetros del Ebro atraviesan 
la región- y catalana, por los problemas que se podían crear en el Parque Natural del Delta del Ebro. Los aragoneses recibieron el trasvase como una mutilación a su desarrollo económico, sobre todo cuando estaba pendiente el Pacto del Agua de Aragón, que preveía la continuación y terminación de los cientos de hectáreas de secano a regadío pendientes de transformación desde los Planes Gasset y Lorenzo Pardo (MORT, 1993).

Por su parte, la Generalitat catalana había aceptado el trasvase a condición de que se redactase un plan de inversiones específico para el Delta del Ebro y exigiendo más tarde un aumento del caudal ecológico para asegurar el Parque Natural. De 100 se pasó a $135 \mathrm{hm}^{3}$ por segundo, un cambio que, a juicio de la Fundación Nueva Cultura, reduce el excedente del Ebro a unos $500 \mathrm{hm}^{3}$, invalidando las bases de la transferencia del agua.

Unos planteamientos refrendados por la Convención Ramsar, organización internacional que protege los humedales de los 123 países que suscribieron el Convenio, al afirmar que el trasvase tendría consecuencias irreversibles, como la regresión del delta, la salinización de su acuífero y daños considerables en la fauna y la flora de uno de los humedales más característicos e importantes del Mediterráneo. Por su parte, la Comisión Europea, tras una recepción tardía de la Evaluación Estratégica Ambiental correspondiente y varias veces solicitada, hizo una lectura positiva en conjunto aunque exigió numerosas modificaciones y ampliaciones como punto de partida para su aprobación definitiva.

Los expertos anti trasvase, sobre todo la Fundación Nueva Cultura del Agua (FNCA), afirmaban que el proyecto no cumplía ninguna de las tres condiciones de un plan hidráulico estructural. Antonio Esteban, portavoz de dicha Fundación enumeraba: "No da garantía, no da calidad y no da coste" (Cr. Vázquez, 2003). El Ebro, continuaba, no ofrece garantía de reserva hídrica por que es un río irregular, con importantes diferencias de caudal no sólo estacionales sino también interanuales. La calidad del agua del Ebro es baja: supera los 1.000 microsieverts por centímetro cúbico y padece una concentración de sales superior a la que la UE recomienda como límite máximo en aguas prepotables. Incluso, la FNCA advertía que las previsiones de la evolución en calidad no se cumplirían ya que el trasvase implicaba un empeoramiento de las condiciones implícitas para la ampliación de los riegos en la cuenca del Ebro, aparte los del Pacto del Agua de Aragón, en La Rioja, Navarra, Lleida.

Finalmente, se añadía, el Plan no aseguraba el coste definitivo del agua: los 31 céntimos de euro estimados no eran válidos porque se aplicaba la misma tarifa a todo el canal a construir, cuando el caudal que llegara 
a Murcia saldría a un precio muy superior, entre 48 y 55 céntimos de euro, máxime cuando se había estimado sin tener en cuenta las pérdidas que se producirían a lo largo de los 912 kilómetros del canal y de los 1.050 hm conducidos y que se estimaba podrían ser reducidos por las pérdidas en un $15 \%$ al menos. Y tampoco se había considerado el hecho de que el trasvase partía de una toma sita a 400 metros por debajo de la altura de llegada lo que, sin duda, elevaría el coste del imprescindible bombeo del agua muy por encima del precio estimado en el Plan 2001.

\section{LA DEROGaCión PARCIAL DEL PLAN DE 2000 Y EL FIN DEL TRASVASE DEL EBRo CON EL PlaN DE 2004}

Esta llamada guerra del agua cambió de signo cuando las elecciones nacionales del año 2004, en cuyas campañas la polémica del trasvase había sido "el eje principal", favorecieron al Partido Socialista. De momento, las limitadas obras iniciadas se detuvieron, y el nuevo Gobierno, cuyos apoyos políticos habían sido reticentes a ciertos aspectos de los Planes adoptados en 2000/01, reanudó las consultas y los análisis sobre el conjunto del proyecto a la par que resurgía la polémica política y social sobre el Programa 2000-2008 entre las distintas autonomías y, en especial, sobre el funcionamiento del trasvase Tajo-Segura y la transferencia desde el Ebro.

Finamente, el Real Decreto-Ley de 18 de junio de 2004, que modificaba "la Ley 10/2001 de 5 de julio", derogó el trasvase del Ebro, la mayor y más discutida obra del Plan Hidrológico de 2000, aunque manteniendo el máximo de las restantes actuaciones previstas de mejora y ampliación del regadío y del abastecimiento urbano y añadiendo aqueIlas otras que sustituían las que debían resultar del desaparecido trasvase del Ebro, y que se enumeraban en los anexos III y IV del Plan de 2000 también mantenidos. Asimismo, modificó levemente el conjunto de los nuevos regadíos a realizar, 130.000 ha en lugar de los 247.700 previstos. Inmediatamente, los Gobiernos valenciano y murciano anunciaron la presentación de sendos recursos ante el Tribunal Constitucional aún no resueltos.

En el Decreto-Ley se justificaba la derogación en "evitar la realización de actuaciones que pueden implicar un despilfarro de recursos e impedir o retrasar la realización de medidas estructurales de inversión y de gestión, que son necesarias para satisfacer las necesidades hídricas de las cuencas mediterráneas, y asegurar la estabilidad de un desarrollo más equilibrado, 
sostenible y concertado en todos los territorios a los que hubiera afectado el trasvase del Ebro".

Una justificación que se ampliaba en el Preámbulo, tanto en lo que se refería a la derogación parcial del Plan Hidrológico como a los cambios introducidos, en una amplia panoplia de razones. En su dimensión económica, se insistía en unos costes del Proyecto infravalorados y, especialmente, en los precios a pagar por los futuros usuarios de los caudales trasvasados, así como en unos beneficios sobreestimados en general pero también en las previsiones del empleo a crear. Desde el punto de vista del medio ambiente, se denunciaba la inexistencia de estudios acerca de los efectos sobre el medio natural exigidos por la Directiva 2000/60 CE de la Unión Europea y por el Protocolo de Kioto recién firmado por España, poniendo como ejemplo palpable los daños que hubieran afectado al Delta del Ebro.

Asimismo, en relación a sus aspectos técnicos, se señalaba, sobre todo, la falta de rigor en los cálculos sobre la disponibilidad real del caudal del Ebro a trasvasar sin perjuicio de las posibilidades de desarrollo de las regiones afectadas y se hacían constantes referencias a la carencia de estudios adecuados sobre las pérdidas de agua que el largo camino a recorrer por el canal del trasvase produciría. Tampoco evaluaba el Plan el consumo de energía y su impacto en el cumplimiento por España del Protocolo de Kyoto, ni el aumento de la salinidad en la cuenca cedente y en las receptoras. Todas estas "graves deficiencias" habían sido determinantes, se añadía, de que las posibilidades de financiación con cargo a los Fondos de Cohesión de la UE no hubieran llegado a buen fin.

Por su parte, el Ministerio de Medio Ambiente propuso como alternativa al derogado trasvase, una aportación al conjunto de las Comunidades de Valencia y Murcia de $1.058 \mathrm{hm}^{3}$ — una cantidad muy similar a la del trasvase $\left(1.050 \mathrm{hm}^{3}\right)$ - anuales de agua, 621 de los cuales serían producto de la desalación y el resto de una mejor gestión y ahorro del agua $(250$ hm³) y la reutilización de $187 \mathrm{hm}^{3}$ de caudales ya usados y reciclados. Aparte de que, en la solución socialista, se partía del principio de que un metro cúbico de agua desalada es tres veces más barato que la misma cantidad de agua trasvasada.

La alternativa —el Ilamado Programa Agua — implicaba la construcción de quince nuevas grandes plantas desaladoras como obra principal, y la ampliación y mejora de otras trece ya existentes o en construcción. Se añadía, como complemento imprescindible, la reutilización masiva de las aguas usadas de todas las grandes poblaciones del Mediterráneo desde Barcelona hasta Marbella, la puesta en marcha de una serie de plantas potabilizadoras 
y todo un conjunto de medidas urgentes de mejora de las conducciones existentes, de prevención de inundaciones y de una amplia restauración medioambiental, aparte de un mini trasvase desde el embalse del Talave al Alto Guadalentín (Murcia).

Además, se mantenía la construcción de nuevos embalses y la creación de nuevos regadíos, como los del Proyecto Aragón, aunque todo el programa debería ser considerado y reformado si era necesario tras unos nuevos estudios sobre sus posibilidades naturales y económicas y la reconsideración en profundidad de las necesidades objetivas y las demandas existentes. Las 112 presas y los consiguientes espacios a irrigar previstos tendrían que superar un riguroso filtro de rentabilidad económica y social antes de obtener luz verde del Ejecutivo. Según la Ministra de Medio Ambiente: "Nos hemos encontrado con embalses que no tienen a quién abastecer porque se iniciaron cuando existía una demanda que ha desaparecido y con presas terminadas hace diez años que están a la espera de que se hagan las conducciones" (J. L. Barbería, 2005). Con estos supuestos, se redujo la superficie a regar de las 280.000 ha previstas en 2001 a sólo unas 130.000 consideradas suficientes e imprescindibles en el año 2005. Estas nuevas infraestructuras se complementaban con un ahorro estimado en unos 844 $\mathrm{hm}^{3}$ por el programa de modernización de los regadíos incluidos en el Plan Nacional de Regadíos H-2008 adjunto al Plan Hidrológico 2004.

Todo ello exigía una inversión aprobada de 3.747 millones de euros repartidos entre Andalucía (579 millones), Cataluña (1.110), Murcia (875) y C. Valenciana (1.219).

El desarrollo del Plan modificado y, en concreto, la alternativa al trasvase, se inició seguidamente, aunque con algunas modificaciones que acentuaron las protestas de la oposición y, en especial, de las Comunidades más afectadas. El Ministerio del Medio Ambiente considerando que el Programa Agua estaba sobredimensionado y que no existía tanta demanda de agua, decidió en noviembre de 2004 la rebaja en una cifra a establecer de los caudales a obtener y distribuir ya que "no se hará ninguna obra si no se tiene garantizado el uso del agua que se provee".

Las desaladoras a construir o ampliar, punto clave en el Plan de 2004, se inauguraron entre los años 2004 y 2005 con cinco plantas sitas en MeliIla $\left(7,5 \mathrm{hm}^{3}\right)$, Ceuta $(7,5)$, Alicante I (24), San Pedro del Pinatar (48) (Murcia) y Carboneras (Almería). Esta última, la mayor hasta el momento, con sus 42 $\mathrm{hm}^{3}$ potenciales de agua salada convertida en dulce — sólo funciona al $15 \%$ - abastece desde entonces a ese municipio, al inmediato de Mojácar y a los invernaderos del Campo de Níjar (figura 6). 
Figura 6. El Plan Hidrológico Nacional de 2004 según el Programa Agua 2004 y EL DIARIO EL PAÍS, 21 DE ENERO DE 2008

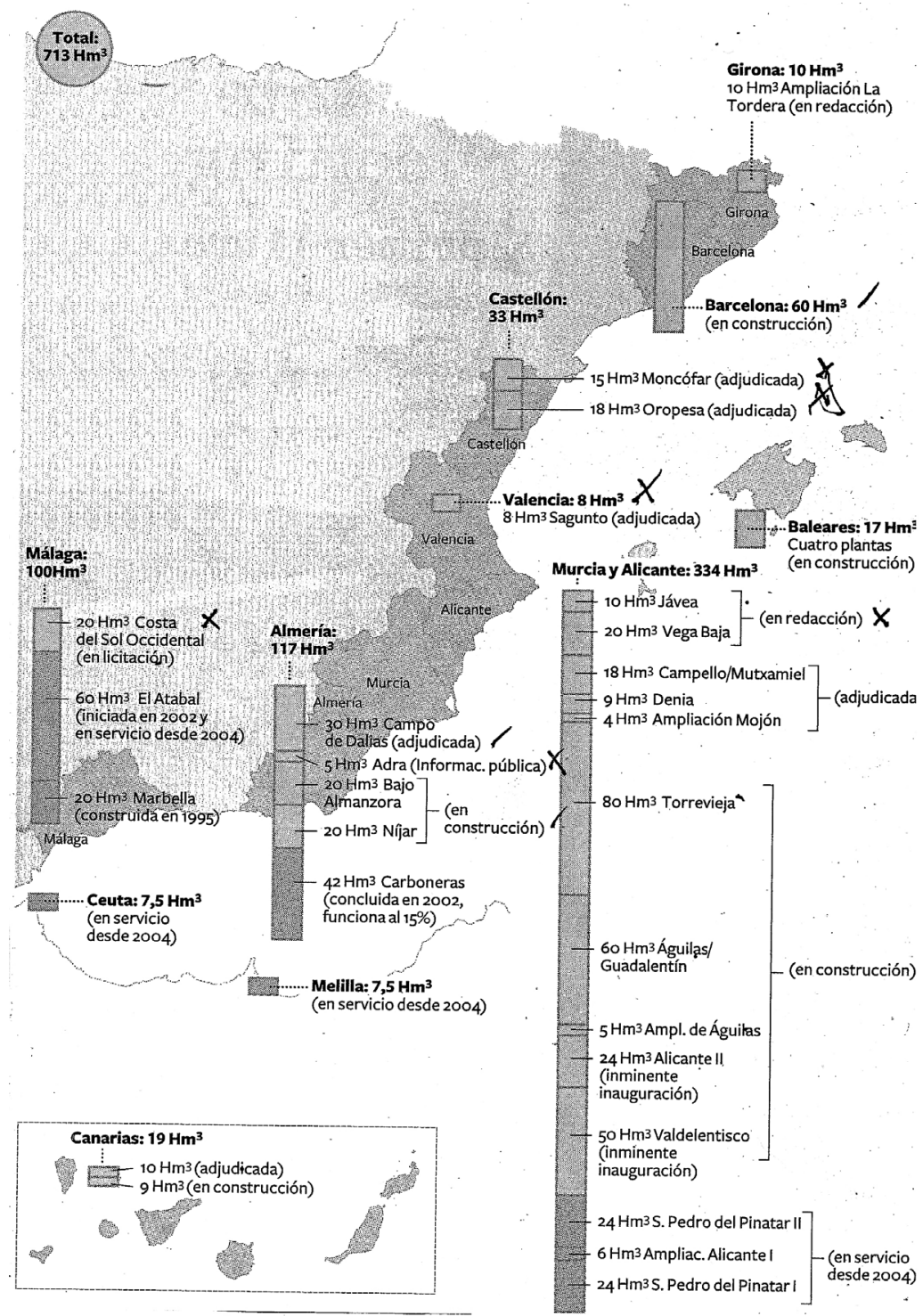

Además, en 2008 estaban en construcción otras diez instalaciones en Barcelona $\left(60 \mathrm{hm}^{3}\right)$, Baleares (4, con un total de $\left.17 \mathrm{hm}^{3}\right)$ Alicante II (24), Torrevieja (80, Alicante), Águilas (65, Murcia), Bajo Almanzora y Níjar (40, Almería) y otras dos de un sistema diferente (ósmosis inversa) en Canarias 
(19 hm³). Y, se habían adjudicado para su iniciación otras ocho en diferentes partes del Levante y el Mediodía español. Finalmente, cinco se encontraban en estudio y redacción. En conjunto, terminadas, proporcionarán 621 hm³, el $58,7 \%$ del total de los $1.058 \mathrm{hm}^{3}$ de agua aportados por el Plan 2004 frente a los 1.050 del trasvase del Ebro derogado.

El programa de desalación ha sido el más combatido y debatido del nuevo Plan Hidrológico. En especial, sus contrarios consideran que el precio del agua desalada supera netamente $-0,90$ euros por $\mathrm{m}^{3}$ - el coste del caudal a trasvasar, calculado en 0,31 euros el $\mathrm{m}^{3}$, a causa del gasto energético y por el deterioro del medio ambiente marítimo por los vertidos derivados de la desalacion. No obstante, afirman los teóricos y técnicos de la desalación, si en los años setenta se precisaban 22 kilovatios por cada metro cúbico desalado, actualmente las nuevas técnicas sólo precisan 2,6 kilovatios, con lo que hoy el precio de la desalación oscila entre 0,45 y 0,71 euros por $\mathrm{m}^{3}$, en todo caso similar o ligeramente inferior al establecido en el trasvase y con claras expectativas de mejoras de futuro. Como precios finales, el Plan de 2004 valora el $\mathrm{m}^{3}$ de agua trasvasada en 0,90 euros y el del agua desalada en 0,33 euros el $\mathrm{m}^{3}$. En este aspecto, conviene recordar que la industria española del ramo es una de las mejores del mundo, con contratos conseguidos en los Estados Unidos, China, la India, Próximo Oriente y norte de África (A. Díaz y J. M. Romero, 2004; J. L. Barbería, 2005).

En conjunto, el plan se está cumpliendo aunque con evidentes demoras, bastante resistencia en algunos casos de las comarcas y las ciudades receptoras y una constante pugna y discusión sobre el coste de la desalación respecto al del trasvase y el precio del agua a pagar por los usuarios. Un debate con muchos pros y contras, excepcionalmente politizado (A. Rico Amorós y otros, 1988; A. Bolaños, 2008). Asimismo, los nuevos regadíos que, en un total de 130.000 ha, formaban parte del modificado Plan, empezaron a ser estudiados seguidamente para su realización dentro del plazo de ocho años establecido.

Un desarrollo del nuevo Plan pleno de incidencias, aparte la intensa oposición partidista y regional derivadas de la continuidad de la sequía que, iniciada a finales de los noventa, se ha mantenido y exacerbado en los primeros años del siglo XXI, hasta convertirse por su duración e intensidad en el bienio 2004-2005 en la peor sequía desde mediados del Novecientos.

En fin, una historia compleja y llena de sorpresas como parece mostrar el hecho paradigmático planteado a lo largo del año 2008 con la situación de extrema escasez de agua potable en el área metropolitana de Barcelona, cuyos embalses en servicio apenas contenían desde finales del año anterior 
una mezcla de agua y lodo por debajo del $20 \%$ de su capacidad de embalse, y que habían obligado a imponer unas restricciones máximas a una población de alrededor de tres millones de personas.

Tal penuria hizo que la Generalitat catalana intentase una solución temporal, en tanto se pusiera en marcha la gran desaladora en construcción a fin de atender el consumo de la región y que debiera estar finalizada en el otoño de 2008. Una solución temporal basada en un proyecto de mínimo trasvase desde el río Segre, el mayor afluente pirenaico del Ebro, al Llobregat y al conjunto hídrico que abastece normalmente a Barcelona y su área metropolitana. Apenas conocido el proyecto y sin que se hubiera aprobado ni iniciado, las declaraciones contrarias se generalizaron.

Primero, por parte del Ministerio del Medio Ambiente que, conforme a lo dispuesto en su Plan Hidrológico de 2004, expresó su oposición a cualquier trasvase no admitido en el Real Decreto Ley aprobado. A su negativa se unió enseguida la del Gobierno de Aragón, contrario a cualquier extracción de agua del Ebro, y no faltaron las protestas dentro de la misma Comunidad catalana. En ese sentido se manifestó el primer partido de la oposición, Convergencia i Unió, pero también las asociaciones de regantes de las Vegas leridanas, las existentes aguas arriba, en el Ebro medio aragonés, y finalmente los responsables técnicos de la conservación del Parque Natural del Delta del Ebro y sus habitantes mediatos e inmediatos. Por su parte, las Comunidades tanto de Valencia como de Murcia manifestaron que tal medida hacía totalmente necesaria la reconsideración del trasvase del Ebro a los ríos levantinos del Plan de 2000.

Los temporales de finales de primavera de 2008, que aliviaron el vaciado de los embalses del entorno de Barcelona y la aceleración de la construcción de la desaladora barcelonina, la mayor $\left(60 \mathrm{hm}^{3}\right)$ de las propuestas, dieron pie a una tregua en el debate que parece al menos amortiguado (Diario El País, 31 de marzo de 2008 y Diario Público, 2 de abril de 2008).

Así, de momento, el Plan Hidrológico Nacional aprobado por el Real Decreto Ley 2/2004 del 18 de junio de 2004 sigue su curso más o menos lentamente una vez ratificado por la renovación en el poder de su máximo valedor, el Partido Socialista Español, en marzo del año 2008.

\section{¿Hacia una "Nueva Cultura del Agua?"}

En último término, el nuevo Plan Hidrológico Nacional aprobado en el año 2004 parecía inaugurar una nueva visión y un nuevo planteamiento de las políticas sobre el agua. Unos cambios, en principio imprescindibles, por 
la aparición de los problemas derivados del hecho, reconocido oficialmente, de ser "el agua un bien escaso", pero cada vez más necesario y consumido y con limitaciones crecientes por ser un "recurso finito" exigido por una población en crecimiento en cifras absolutas y, más aún, en la homogeneización de sus exigencias y, a la vez, en su diversidad cultural.

Tradicionalmente, el uso del agua como el de todos los recursos naturales precisos para el sostenimiento de la humanidad partía de un principio recogido por el Génesis $(1,28)$ al afirmar, “... y los bendijo Dios, diciéndoles: creced y multiplicaos, y henchid la tierra; sometedla y dominad sobre los peces del mar, sobre las aves del cielo, y sobre todo cuanto vive y se mueve sobre la tierra". Un uso y abuso iniciados con el Hombre pero cuya incidencia en el medio ambiente terrestre fue importante pero mínimo en función de los límites de unas tecnologías basadas en la utilización directa de ciertos recursos naturales, el fuego, el agua y el viento $y$, sobre todo, la fuera animal, en gran medida humana (S. Lilley, 1965). Unos usos que comenzaron, convirtiéndose en abusos, a hacerse, a veces, peligrosos para la subsistencia de la población terrestre, desde que la Revolución socioeconómica iniciada en los siglos XVI y XVII, y, en especial, la Industrial del $\mathrm{XVIII}$, desencadenó un crecimiento exponencial tanto del uso de los recursos naturales como de sus mismos usuarios. La incidencia resultante en la naturaleza dejó de ser meramente coyuntural y local/regional para convertirse, en muchos casos, en terrestre y universal con posibles amenazas a la misma realidad de la Tierra como un "hecho único" e "irrepetible" (L. Urteaga, 1987; J. Bosque Maurel, 1995).

Sólo muy recientemente, en los últimos doscientos años, como ha señalado Velarde Fuertes (2007), se han ido denunciando una serie de "profecías" desencadenados por el desarrollo tecnológico de la humanidad, Malthus y su temor al crecimiento desmesurado de la población, el final de las materias primas, el cambio climático. Riesgos superados en principio aunque nunca se pueden negar plenamente algunas consecuencias muy negativas derivadas de ese desarrollo socioeconómico, como el desequilibrio social y político entre unas partes y otras de la Tierra, la contaminación atmosférica creciente y la destrucción puntual o comarcal de la naturaleza, ni la seguridad absoluta de su contención.

De aquí que, en los últimos treinta años, se hayan producido a nivel mundial, y con el apoyo y, a veces, con la misma intervención directa de las Naciones Unidas, campañas de concienciación de defensa del medio ambiente $y$, en especial, de limitación de ciertos usos y/o abusos contrarios a la sustentabilidad futura del desarrollo tanto de la naturaleza como de la 
humanidad en su devenir a nivel terrestre y con similares posibilidades para toda la humanidad. Por ejemplo, la Cumbre de la Tierra de 1992 en Río de Janeiro y sus epílogos subsiguientes hasta el Protocolo de Kioto de 1997 y, especialmente, el Informe Nuestro futuro común de la Comisión Mundial del Medio Ambiente y del Desarrollo, presidida por la política noruega Gro Harlem Bruntland y patrocinada por las Naciones Unidas en 1988 en apoyo de "un programa global para el cambio" que defendiera y generalizara unos principios de progreso "sustentable" $y$, difundiera, unas medidas y unas normas que justificasen unas actuaciones a favor de la "sustentabilidad" futura de la humanidad.

Planteamientos universales que han conducido a consideraciones más concretas y monográficas. En esa línea se mueve la Fundación para una Nueva Cultura del Agua, nacida en 1998 en Zaragoza, extendida enseguida a Lisboa y cuyos principios han sido el resultado de seis Congresos Internacionales con inicio en 1998 y un sexto convocado para finales del año 2008. La Fundación cuenta actualmente con el apoyo de setenta universidades españolas, europeas y americanas y está sostenida por un centenar de socios fundadores pertenecientes a veinte naciones europeas. Casi un centenar de publicaciones de carácter general y de informes técnicos de carácter monográfico avalan su profunda preocupación conceptual y su incansable actividad investigadora, empírica y tecnológica. Todo ello ha culminado en una "Declaración del Agua" apoyada por más de un centenar de expertos pertenecientes a muy diferentes culturas.

El punto de partida de esta Nueva Cultura del Agua es una afirmación de las Naciones Unidas: "Por debajo de $1.700 \mathrm{~m}^{3}$ de agua por individuo al año, la población está en una situación de estrés hídrico". Pero, continúa, "más de la mitad de la humanidad no llega a la posibilidad de contar ni siquiera con una cuarta parte de las cifras de ese "estrés hídrico". Afirmación que forma parte de la doctrina de la Sustantibilidad de la Sociedad y la Economía de la Humanidad provocada y sostenida por la misma ONU. En la Presentación en Internet de la Fundación se escribe: "Quizá las privilegiadas sociedades occidentales de hoy puedan permitirse la opción de la huida hacia delante, realimentando espirales de insostentibiliad. Pero esto sólo es posible desde la inmoralidad de sacrificar los derechos de las generaciones futuras y acrecentar las injusticias planetarias presentes. La lucha contra la pobreza, la ecoeficiencia y la conservación de nuestros patrimonios de la naturaleza son claves de un reto de responsabilidad ética que hoy debemos asumir".

A partir de aquí, la preocupación por llegar a una nueva visión de las políticas y los problemas del agua conduce a la Fundación a sostener: "Sin 
duda la tradicional política hidráulica se queda hoy corta para recoger las necesidades e inquietudes de nuestra sociedad y dar respuestas adecuadas a los retos que se derivan del nuevo paradigma de la sostentibilidad. Conciliar la aspiración a mejorar el bienestar de todos con el reconocimiento y respeto a los límites del entorno natural de manera que se garantice su conservación, exige no sólo un giro en los objetivos de esta política, sino también un cambio en las escalas de valor y en la cultura que impregna nuestra sociedad".

De manera más concreta y específica, el profesor Dr. Pedro Arrojo Agudo, uno de los abanderados de la nueva cultura del agua y un crítico del Plan Hidrológico Nacional por razones no sólo ambientales sino también económicas, define y explica con un sencillo ejemplo sus fundamentos ideológicos: "La nueva cultura del agua invita a mirar los ríos y a entender que son mucho más que canales de $\mathrm{H}_{2} \mathrm{O}$. Es entender que un ecosistema, además de agua que puede usarse para producir, es paisaje, identidad territorial, identidad de los colectivos y comunidades sociales, valores lúdicos y culturales, valores de vida... Y que a través de esos ríos se articula la vida en el continente y en los mares. Los ríos no se pierden en el mar, fertilizan las plataformas litorales y muchos peces del mar dependen de los ríos. Y si hay playas es por la erosión, así que las industrias turísticas dependen también de los ríos. La cultura del agua es entender esta complejidad de ecosistemas" (Pedro Arrojo Agudo, cit. por A. Calvo Roy, Diario El País, 2004).

La Exposición Internacional 2008 de Zaragoza con su lema "Agua y desarrollo sostenible" se encuentra en la misma línea de la Nueva Cultura del Agua. En una Tierra en el que sólo el 1\% del agua es potable y no puede abastecer a una demanda que se ha duplicado en dos décadas, con millones de personas que carecen de acceso a su uso, el derecho al agua, la exigencia de una nueva forma de entender y gestionar el agua escasa, se ha convertido en el gran debate, imprescindible y urgente, del siglo XXI.

Recibido 16.07.08

Aceptado 06.10.08

\section{BIBLIOGRAFÍA}

AA. VV. (1989): Los paisajes del agua, Universitat de Valencia y Universidad de Alicante, Valencia, 394 pp. [libro jubilar dedicado al profesor Antonio López Gómez].

AA. VV. (1994): Demandas y usos del agua en España. № monográfico del Boletín de la Asociación de Geógrafos Españoles, 18, 133 pp. 
AA. VV. (2006): "Zaragoza 2008. Exposición Internacional. La 'Expo' del Agua", Diario El País, 26 de junio de 2006, 15 pp.

Anuario El País (1991-2007), Ediciones El País, Madrid.

Arrojo Aguado, P. (1998): "El agua a debate desde la Universidad: hacia una nueva cultura del agua", Congreso Ibérico sobre Gestión y Planificación del Agua, Zaragoza.

Arrojo Aguado, P. (2001): El Plan Hidrológico Nacional a debate, Nueva Cultura del AguaBaker, Bilbao, 487 pp.

Arrojo Aguado, P. (2003): El Plan Hidrológico Nacional, una cita frustrada con la historia, RBA, Barcelona, 207 pp.

Arrojo Agudo, P. (2005): Lo público y lo privado en la gestión del agua: experiencias y reflexiones para el siglo XXI, Ediciones del Oriente y el Mediterráneo, Madrid-Guadarrama, 364 pp.

Arrojo Agudo, P. (2008): "La sed de Barcelona tiene solución", Diario El País, 7 de abril de 2008, p. 31.

Barbería, J. L. (2005): "El fin del modelo de presa y trasvase", Diario El País, 30 de junio de 2005, pp. 17 y 18.

Barrenechea, E. (1974): "La batalla por el Ebro desde el frente catalán. Cataluña, estupefacta", Diario Informaciones, 3, 4, 5 y 6 de diciembre de 1974, y "La batalla del Ebro desde el frente aragonés. No defendemos Aragón sino a la España pobre", Diario Informaciones, 10, 11 y 12 de diciembre de 1974.

Bolaños, A. (2008): “¿La apuesta por las desaladoras hace aguas?", Diario El País, 21 de enero de 2008, pp. 36 y 37.

Bosque Maurel, J. (1995): "Algunas reflexiones sobre los espacios naturales protegidos", Jornadas sobre Desarrollo Rural en la Sierra de Segura (octubre de 1994), UNAM, Jaén, pp. 183-197.

Bosque Maurel, J. (2007): "Andalucía, ayer y hoy", VIII Congreso de la Asociación Andaluza de Ciencia regional (AACR), Instituto de Desarrollo Regional, Granada, pp. 31-44.

Brunhes, J. (1904) : L'irrigation, ses conditions, ses modes et son organisation dans la Péninsule Ibérique et dans l'Afrique du Nord, Masson, París, XVI + 547 pp.

Cabo Alonso, A. (1990): "Condicionamientos geográficos", Historia de España Alfaguara, Alianza Editorial, Madrid, pp. 1-183.

Calvo Roy, A. (2004): "Pedro Arrojo, Profesor de Análisis Económico", Diario El País, 11 enero 2004, pp. 6 y 7.

Cañas, G. A. y Lucas, B. (2004): "70 ciudades de más de 15.000 habitantes no cumplen el tratamiento de aguas residuales", Diario El País, 2 agosto 2004, p. 22.

Caro Baroja, J. (1988): Tecnología popular española, Madrid,

Comisión Mundial del Medio Ambiente y del Desarrollo (1988): Nuestro Futuro Común, Alianza Editorial, Madrid, 460 pp.

Costa Martínez, J. (1880-1892): Política hidráulica (misión social de los riegos en España) [nueva edición (1975) con apéndice y notas de F. Sáez Ridruejo], Colegio de Ingenieros de Caminos, Canales y Puertos, Madrid.

Diario El País (2007): "El Ebro arrasa la cosecha", 5 abril 2007.

Diario El País (2008): "Las comarcas niegan agua a Barcelona", 31 marzo 2008, pp. 13 y 14.

Diario Público (2008): "Tregua en la guerra del agua", 2 abril 2008, p. 22.

Díaz, A. y Romero, J. M. (2004): "Cara a cara sonbre el trasvase del Ebro", Diario El País, 7 junio 2004, pp. 26, 27 y 28.

Embid Irujo, A. (dir.) (1993): El Plan Hidrológico Nacional, Civitas, Madrid.

Espanya Forcadell, A. (1996): "El Parque Natural del Delta del Ebro: una importante zona húmeda de elevada humanización", Boletín Real Sociedad Geográfica, CXXXVII, aportación al XXVIII Congreso Unión Geográfica Internacional (Los Espacios Naturales Protegidos en España), pp. 119-133. 
Fernández Marco, J. I. (1961): El Canal Imperial de Aragón. Estudio geográfico, Departamento de Geografía Aplicada, Zaragoza, 179 pp.

Gil Olcina, A. y Morales Gil, A. (eds.) (1995): Planificación Hidráulica en España, Fundación Caja del Mediterráneo, Alicante.

Ferreras Chasco, C. (1996): "Las Tablas de Daimiel, ¿un Parque Nacional en peligro de extinción?", Boletín Real Sociedad Geográfica, CXXXII, aportación al XXVIII Congreso de la Unión Geográfica Internacional (Los Espacios Naturales Protegidos en España), pp. 219242.

Galán, L. (2007): "800 núcleos urbanos incumplen la directiva de depuración de aguas residuales", Diario El País, 19 febrero 2007, p. 39.

Gil Olcina, A. y Morales Gil, A. (eds.) (1999): Los usos del agua en España, Caja Ahorros Mediterráneo y Universidad de Alicante, Alicante, 400 pp.

Iranzo, E. y Sanz Donaire, J. J. (dirs.) (2006): Mitos y realidades del Cambio Climático, estudio introductorio de J. Velarde Fuertes, Monográfico Revista Instituto Estudios Económicos, 3 y 4, Madrid, 407 pp.

Jovellanos, G. M. de (1994): Informe de la Sociedad Económica del País de Madrid al Rey y Supremo Consejo de Castilla en el expediente de Ley Agraria, edición facsímil de la nueva edición de 1820, Ministerio de Agricultura, Pesca y Alimentación, Madrid, $239 \mathrm{pp}$.

Lilley, S. (1965): Hombres, máquinas e historia, Ciencia Nueva, Madrid, 359 pp.

López Bermúdez, F. (1969): "El trasvase Tajo-Segura", Estudios Geográficos, XXXV, pp. 320330.

López Galvez, J. y Naredo, J. M. (eds.) (1997): La gestión del agua de riego, col. Economía y Naturaleza 8, Fundación Argentaria, Madrid.

López Gómez, A. (1951): "Riegos y cultivos en la Huerta de Alicante. Evolución y estado actual", Estudios Geográficos, XII, 44, pp. 701- 771 + VIII láminas.

López Gómez, A. (1971): “Embalses de los siglos XVI y XVII en Levante", Estudios Geográficos, XXXII, pp. 617-656.

López Gómez, A. (1974): "El origen de los riegos valencianos. Los canales romanos", Cuadernos de Geografía, 15, pp. 1-24 + IV láminas.

López Gómez, A. (org.) (1983): "Lluvias excepcionales e inundaciones en la vertiente mediterránea oriental española en octubre-noviembre de 1982", n monográfico de Estudios Geográficos, XLIV, 170-171, pp. 3-316.

Lorenzo Pardo, M. (1931): "La conquista del Ebro", Heraldo de Aragón, Zaragoza.

Lorenzo Pardo, M. (1933): Plan Nacional de Obras Hidráulicas, nueva edición comentada (1993), 2 vols, MOPTMA, Madrid.

Llanos, C. de los (1990): L'Andalousie dans l' Europe. L'essor du secteur fruitier et maraîcher, publicaciones de la Casa de Velázquez, Serie Recherches en Sciences Sociales, X, Casa de Velázquez, Madrid, 178 pp.

Macías Picabea, R. (1899): El problema nacional: hechos, causas, remedios, publicada en 1991 en la Biblioteca Regeneracionista, Fundación Banco Exterior, Madrid, 260 pp.

Marsal, J. (2001): "El organismo internacional que protege los humedales rechaza el Plan Hidrológico", Diario El País, 7 septiembre 2001, p. 24.

Masachs Alavedra, V. (1954): "Las grandes arterias fluviales", Península Ibérica. Geografía física, II, Muntaner y Simón, Barcelona, pp. 106-142.

Méndez, R. (2005): "La conversión de 350.000 hectáreas en regadío en 10 años agrava la sequía", Diario El País, 16 mayo 2005, p. 30.

Méndez, R. (2008): "10 claves de la guerra del agua", Diario El País, 16 abril 2008, p. 16.

Méndez, R. (2003): "El Foro del Agua afirma que el ritmo de consumo es insostenible", Diario El País, 17 marzo 2003, p. 33.

Méndez, R. (2007): "El precio del agua tendrá que subir un $15 \%$ por el plan de calidad de ríos", Diario El País, 8 junio 2007, p. 38. 
Menéndez Rexach y Díaz Lema, J. M. (1986): "La Ley de Aguas de agosto de 1986. Análisis Institucional", en Gallego Anabitarte, A. y otros, El Derecho de Aguas en España, vol. I, $3^{\mathrm{a}}$, MOPU, Madrid.

MOPT (1993): Plan Hidrológico Nacional. Memoria y Anteproyecto de Ley, 2 vols., Ministerio de Obras Públicas, Madrid.

Mor de Fuentes, J. (1952): Bosquejillo de la vida y escritos de D. José Mor de Fuentes delineado por él mismo, prólogo, edición y notas de Manuel Alvar, Universidad de Granada, $198 \mathrm{pp}$.

Moral Ituarte, L. del (1994): "Elementos para una teoría de los conflictos territoriales sobre el agua", Boletín Asociación Geógrafos Españoles, 18, pp. 9-27.

Morales Gil, A.; Rico Amorós, A. M. y Hernández Hernández, Ma (2005): “El trasvase TajoSegura", Observatorio Medioambiental, 8, pp. 73-110.

Nadal Raynat, E. (1981): "El regadío durante la Restauración. La política hidráulica (18751902)", Agricultura y Sociedad, 19, pp. 129-161.

ONU (1977): Conferencia de las Naciones Unidas sobre el Agua. Mar del Plata (Argentina), marzo 1977, número monográfico de la Revista de Obras Públicas, 31.144, abril 1977.

Ortega Cantero, N. (1979): "Política agraria y dominación del espacio. Orígenes, caracterización y resultados de la política de colonización planteada en la España posterior a la guerra civil", Ciudad y sociedad, 5, Editorial Ayuso, Madrid, 258 pp.

Pillet Capdepón, F. (2001): "La Mancha. Transformaciones de un espacio rural", Biblioteca Añil, 12, Celeste Ediciones, Madrid, 180 pp.

Rico Amorós, A. y otros (1998): Depuración, desalación y reutilización de aguas en España, Oikos-Tau, Barcelona, 255 pp.

Romero González, J. (1995): “El Plan Nacional de Obras Hidráulicas. Precedentes y Condicionantes", en Gil Olcina, A. y Morales Gil, A., Planificación Hidráulica en España.

ROP (1997): "El Delta del Ebro", Revista de Obras Públicas, nº monográfico, 3.368.

Sanz García, J. Ma (1988): "Los canales del Guadarrama y Manzanares de Juan II a Juan Carlos I pasando por Carlos III", Ciclo de Conferencias: el Madrid de Carlos III, 11, Instituto de Estudios Madrileños, Madrid, 68 pp. + 7 láminas.

Terán, M. de y Solé Sabarís, L. (dirs.) (1994): Geografía General de España, Ariel Geografía, Barcelona, $495 \mathrm{pp}$.

Urteaga, L. (1987): La tierra esquilmada, Serbal y CSIC, Madrid, 221 pp.

Vázquez, Cr. (2003): "La polémica del Plan Hidrológico. La promesa del agua", Diario El País, 19 marzo 2003, pp. 28 y 29.

Velarde Fuertes, J. (1968): Política económica de la Dictadura, Biblioteca Universitaria de Economía, 1, Guadiana de Publicaciones, Madrid, 158 pp.

Velarde Fuertes, J. (1996): Hacia otra economía española, Espasa-Calpe, Madrid.

\section{Resumen}

El agua es, en España, un bien esencial pero también escaso, mal repartido y muy debatido. Desde su uso como base de los cultivos desde la Antigüedad, el desarrollo de las técnicas del agua ha conducido a más de cuatro millones de hectáreas de regadío repartidas por todo el territorio español. Pero también a un consumo creciente y vario difícil de atender en las regiones más secas del Estado caracterizado por un grave desequilibrio territorial que enfrenta el noroeste con el sudeste. Su solución necesaria ha dado lugar a soluciones a menudo muy politizadas como los sucesivos Planes Hidrológicos Nacionales planteados en 1994, 2001 y 2004.

Palabras clave: geografía humana; geografía agraria; el agua; recurso escaso; secano y regadío; Planes Hidrológicos Nacionales. 


\section{Abstract}

In Spain, water is an essential resource that is scarce, badly distributed and much talkedabout. Although water has been the basis for agriculture since old, the developement of modern water technology has resulted in more than four million hectares of irrigated land spread all over the Spanish land. But it has also led to a growing and diverse consumption of water that is not easily met in the drier regions of Spain, a State the main feature of which is a serious territorial rain imbalance that turns the Northwest versus the Southeast. Its muchneeded solution has been approached in politically-viewed projects such as the National Hydrological Plans of 1994, 2001 and 2004.

Keys words: human geography; agrarian geography; water; a scarce resource; dry farming and irrigation farming; National Hydrological Plans. 